\title{
Checklist de Porifera do Estado de São Paulo, Brasil
}

\author{
Márcio Reis Custódio ${ }^{1,2}$ \& Eduardo Hajdu E $^{3,4}$ \\ ${ }^{1}$ Departamento de Fisiologia Geral, Instituto de Biociências, Universidade de São Paulo - USP, \\ Rua do Matão, Travessa 14,n. 101, CEP 05508-900, São Paulo, SP, Brasil,e-mail: mcust@ usp.br \\ ${ }^{2}$ Centro de Biologia Marinha, Universidade de São Paulo - USP, \\ Rod. Manoel Hypolito do Rego, Km 131,5. CEP 11600-000, São Sebastião, SP, Brasil \\ ${ }^{3}$ Departamento de Invertebrados, Museu Nacional, Universidade Federal do Rio de Janeiro - UFRJ, \\ Quinta da Boa Vista, s/n., CEP 20940-040, Rio de Janeiro, RJ, Brasil \\ ${ }^{4}$ Autor para correspondência: Eduardo Hajdu, e-mail: eduardo.hajdu@gmail.com
}

CUSTÓDIO, M.R. \& HAJDU, E. Checklist of Porifera from São Paulo State, Brazil. Biota Neotrop. 11(1a): http://www.biotaneotropica.org.br/v11n1a/en/abstract?inventory+bn0151101a2011.

\begin{abstract}
The sponges (Porifera) are one of the oldest extant metazoans, but still easily found in a wide variety of aquatic environments. They are key components in several ecosystems, directly influencing the quality of water in their habitat. In recent times, these organisms have become one of the most productive groups in providing new compounds with bioactivity or unusual structures. However, sponges are historically considered a group of complex taxonomy, and systematic discussions at order level or even about the monophyly of the group are still common. This situation began to change markedly in the last decade, with multinational initiatives aimed at providing a more solid taxonomic basis. In Brazil, this process was accompanied by the publication of identification guides of the native species. Starting from the sporadic data available in earlier periods, several initiatives were specifically targeted at the survey of Porifera species, particularly in coastal regions. Such actions now provide the researchers with a knowledge base far more comprehensive than that available a decade earlier. In the ten years since the last checklists for the São Paulo State were published, there was a significant change in the scenario. As verified by this study, the period was undoubtedly the most prolific regarding the knowledge of the local spongiofauna. Keywords: Porifera, biodiversity of the State of São Paulo, BIOTA/FAPESP Program.
\end{abstract}

Number of species: in the world: 8,344, in Brazil: 400, estimated in São Paulo State: 300.

CUSTÓdiO, M.R. \& HAJdU, E. Checklist dos Porifera do Estado de São Paulo, Brasil. Biota Neotrop. 11(1a): http://www.biotaneotropica.org.br/v11n1a/pt/abstract?inventory+bn0151101a2011.

Resumo: As esponjas (Filo Porifera) são um dos metazoários mais antigos existentes, mas ainda facilmente encontradas em uma grande variedade de ambientes aquáticos. São um componente fundamental em diversos ecossistemas, influenciando diretamente a qualidade da água em seus habitats. Em tempos recentes são um dos grupos que mais fornece novas moléculas bioativas ou com estruturas incomuns. No entanto, são historicamente considerados um grupo de taxonomia complexa e ainda são comuns discussões acerca da sistemática ao nível de ordens ou mesmo da monofilia do grupo. Este cenário começou a ser alterado de forma marcante na última década, a partir de iniciativas multinacionais voltadas a fornecer uma base taxonômica mais sólida. No Brasil, este processo foi acompanhado pela publicação de guias de identificação para as esponjas do nosso litoral. Partindo dos dados esporádicos disponíveis em períodos anteriores, diversas iniciativas foram feitas especificamente voltadas para o levantamento das espécies de Porifera, principalmente nas regiões costeiras. Tais ações fornecem atualmente aos pesquisadores iniciantes uma base de conhecimento bem mais abrangente do que a disponível na década anterior. Nos dez anos passados desde as últimas listagens feitas para o Estado de São Paulo, houve uma alteração significativa no quadro apresentado. Conforme pôde ser verificado neste trabalho, o período foi sem sombra de dúvida o mais prolífico no que se refere ao conhecimento da espongiofauna local.

Palavras-chave: Porifera, biota paulista, Programa BIOTA/FAPESP.

Número de espécies: no mundo: 8.344, no Brasil: 400, estimadas no Estado de São Paulo: 300. 


\section{Introdução}

As esponjas (Filo Porifera) são consideradas como um dos metazoários mais antigos existentes, com origens estimadas em torno de 800-900 milhões de anos (Müller 1998). São um dos organismos mais comuns em uma grande variedade de ambientes aquáticos. Componentes abundantes em regiões tropicais, são facilmente encontradas nas regiões polares, e em profundidades que vão desde a zona entre-marés até as fossas abissais. Mesmo em corpos de água doce podem representar parte importante da biomassa da megafauna bentônica (Frost et al. 1982, Melão \& Rocha 1999). Seu sistema de filtração é extremamente eficiente. Já foi verificado que esponjas de cerca de $1 \mathrm{~kg}$ são capazes de bombear mais de $10.000 \mathrm{~L}$ de água por dia, retendo desde matéria orgânica coloidal até partículas de $50 \mu \mathrm{m}$ (De Goeij et al. 2008, Weisz et al. 2008). Neste processo, podem absorver carbono correspondente a dois terços de sua massa, sem apresentar crescimento significativo (De Goeij et al. 2009). Desta forma, são extremamente importantes nos ecossistemas onde se encontram, influenciando diretamente a qualidade da água em seus habitats.

Esponjas são conhecidas também por abrigar diversos organismos. Estas associações são extremamente variadas, e incluem crustáceos (Ribeiro et al. 2003, Abdo 2007), poliquetos (Çinar et al. 2002), equinodermos (Turon et al. 2000, Henkel \& Pawlik 2005) e peixes (Rocha et al. 2000). Além dos componentes da macrofauna associada, há também uma microfauna abundante e bastante diversificada, que inclui bactérias, algas e fungos, em alguns casos representando mais de $60 \%$ da biomassa total (Wilkinson 1978, Bugni \& Ireland 2004). Embora as exatas relações sejam em grande parte ainda desconhecidas, sabe-se que estes microorganismos são fundamentais para a fisiologia dos hospedeiros. Desta forma, são especificamente mantidos e controlados, fato evidenciado pela presença de tipos celulares especializados que mantém bactérias em seu citoplasma (bacteriócitos - Vacelet \& Donadey 1977) e também pela transmissão parental de cepas específicas (Enticknap et al. 2006, Sharp et al. 2007).

Poríferos têm portanto uma posição filogenética basal de alta relevância para estudos da evolução dos sistemas multicelulares e são um componente fundamental em estudos ecológicos. Adicionalmente, ocupam uma posição de destaque no que se refere à pesquisa aplicada. Em anos recentes, este grupo tem sido um dos mais prolíficos, dentre toda a diversidade biológica, em fornecer novas moléculas bioativas ou com estruturas incomuns (ver Blunt et al. 2009, e revisões anteriores desta série). Vários compostos foram isolados de diferentes espécies e testados quanto a uma grande variedade de mecanismos de ação, que vão desde atividade antimicrobiana e antiviral, à citotóxica e anti-inflamatória. A diversidade de estruturas químicas é enorme, incluindo terpenos, nucleosídeos, peptídeos cíclicos e alcalóides (Sipkema et al. 2005). Tendo em vista este potencial para a pesquisa de cunho aplicado, diversas iniciativas têm sido tomadas especificamente focando a investigação de novos compostos, inclusive com a formação de empresas dedicadas ao tema, e.g. BIOTECHmarin (Alemanha), PoriFarma (Holanda), PharmaMar (Espanha). Pesquisas feitas com material coletado no litoral de São Paulo também têm sido bastante promissoras. Compostos isolados de diferentes esponjas obtidas em São Sebastião (litoral norte) mostraram atividades citotóxicas específicas contra células tumorais (Rangel et al. 2006), contra o vírus causador da síndrome respiratória aguda severa (SARS). Lira et al. 2007), além de antibioticidade contra diversas cepas de microorganismos patogênicos (Seleghim et al. 2007).

Todas estas iniciativas necessitam fundamentalmente de uma base taxonômica bem estabelecida. No entanto, esponjas são organismos extremamente diversos, que apresentam relativamente poucos caracteres morfológicos suficientemente estáveis nos quais se basear para uma identificação segura. Além disso, sua fisiologia é pouco conhecida, o que torna difícil estabelecer corretamente parâmetros de variabilidade de seus caracteres, mesmo intraespecificamente. Desta forma, são historicamente consideradas um grupo de taxonomia complexa. Atualmente persistem discussões acerca do arranjo e relações sistemáticas ainda ao nível de ordens (Boury-Esnault 2006), e mesmo a respeito da monofilia do grupo (Borchiellini et al. 2001). Um marco importante no sentido de resolver este problema foi a publicação do Systema Porifera (Hooper \& van Soest 2002). Nesta obra, que consiste de mais de 1700 páginas divididas em dois volumes, todos os táxons superiores em Porifera foram revisados com base preponderantemente no exame de seu material tipo. Desta forma, propuseram-se extensas listas de sinônimos, diagnoses e chaves de identificação para todos os táxons julgados válidos, e pela primeira vez em quase dois séculos unificaram-se os sistemas paralelos de classificação, em um único sistema aceito pela ampla maioria dos taxonomistas dedicados ao estudo do filo. Esta pedra fundamental viabilizou algumas iniciativas multinacionais que visam consolidar a taxonomia, tais como a World Porifera Database (WPD), o Sponge Barcoding Project (SBP) e o The Porifera Tree of Life Project (PORTOL). Ao nível nacional, este processo foi acompanhado pela publicação de guias de identificação com descrições detalhadas e específicos para as esponjas do nosso litoral (e.g. Mothes et al. 2003, Muricy \& Hajdu 2006, Muricy et al. 2008). Embora ainda em constante desenvolvimento, essas ações atualmente fornecem aos pesquisadores iniciantes pontos de partida bem mais sólidos do que os disponíveis até a década de 1990.

Nos dez anos passados desde as últimas listagens feitas para o Estado de São Paulo (Hajdu et al. 1999, Volkmer-Ribeiro 1999), houve uma alteração significativa no quadro apresentado. Partindo dos dados esporádicos disponíveis em períodos anteriores, diversas iniciativas foram feitas especificamente voltadas para o levantamento das espécies de Porifera, principalmente nas regiões costeiras. Conforme mostrado a seguir, o período foi sem sombra de dúvida o mais prolífico no que se refere ao conhecimento da espongiofauna local.

\section{Metodologia}

Para a elaboração da lista, foram feitas consultas ao Banco de Dados de Porifera (Museu Nacional. UFRJ), somados a buscas na ISI Web of Knowledge (Thomson Reuters. Todas as databases, incluindo anais e patentes), PubMed (NCBI) e SCIELO. Buscas complementares também foram efetuadas nos acervos digitais de teses e dissertações de diversas instituições nacionais de ensino superior com reconhecida atuação na área (viz. USP, UNICAMP, UNIFESP, UNESP, UFRJ, UERJ, UFPR, UEL, UFSC e UFRGS). Em todas as buscas, foram utilizadas expressões de pesquisa pouco restritas: [(porifera OR sponge*) AND (brasil* OR brazil*)] para os bancos de dados estrangeiros, e [porifera OU esponja*] no caso dos nacionais. Obtidos os resultados, estes foram verificados para exclusão de duplicatas e referências a outras "esponjas" (eg. vegetais, cirúrgicas ou metálicas) ou a trabalhos em paleontologia e sedimentologia. As publicações contendo descrições taxonômicas completas, citações de ocorrência e utilização de esponjas no Estado de São Paulo foram então selecionadas e utilizadas para compor a lista de espécies. Sempre que possível, a identificação atribuída a alguns exemplares nas publicações originais foram atualizadas de acordo com a classificação vigente. A organização taxonômica das espécies segue a sistemática adotada no Systema Porifera (Hooper \& van Soest 2002) e no World Porifera Database (van Soest et al. 2008).

\section{Resultados e Discussão}

Segundo o WPD, em julho de 2010 havia no mundo exatas 8.344 espécies reconhecidas de poríferos, de um total estimado acima de 15.000. No entanto, estes registros ainda são desiguais em 
termos geográficos. Áreas com atividade de pesquisa historicamente mais ativas, como o Caribe e Mediterrâneo, concentram a maioria dos registros. Outras, como os entornos da América do Sul e África são ainda muito pouco investigadas. O Brasil conta com cerca de 350 espécies descritas, sendo 295 para o ambiente marinho (Zilberberg et al. 2009) e 55 para águas continentais (Batista et al. 2007, Pinheiro 2007, Volkmer-Ribeiro et al. 2009, 2010). Embora o número de trabalhos publicados em sistemática e biogeografia tenha aumentado expressivamente nos últimos anos, esta ainda é considerada como uma das áreas menos exploradas do mundo (Muricy et al. 2008, Zilberberg et al. 2009).

O último levantamento realizado a respeito de esponjas marinhas em São Paulo (Hajdu et al. 1999) mostrava que das cerca de 140 espécies registradas em São Paulo, apenas 34 haviam sido publicadas (De Laubenfels 1956, Rocha 1995). E destas, apenas seis haviam sido descritas apropriadamente (Boury-Esnault 1973, Mothes 1980, Hajdu \& Boury-Esnault 1991, Hajdu \& Desqueyroux-Faúndez 1994, Carballo \& Hajdu 1998). No levantamento correspondente sobre esponjas de águas continentais (Volkmer-Ribeiro 1999), apenas seis espécies haviam sido registradas.

A revisão da literatura disponível e dos bancos de dados revela que existem atualmente 158 espécies de Porifera citadas para os ambientes marinho e de águas continentais no estado (Tabela 1). Destas, 144 são pertencentes à classe Demospongiae e 13 à classe Calcarea, uma adição importante à listagem atual. Anteriormente, apenas duas espécies haviam sido registradas: Clathrina primordialis e Guancha blanca (Borojevic 1971, Mothes 1985). Da mesma forma, a Classe Hexactinellida passou a contar com um registro (Hyalonema sp.), feito recentemente em águas profundas (Sumida et al. 2004). Para águas continentais, o número de esponjas passou das seis registradas até 1999 para 12.

Embora expressivos, estes números ainda são mais baixos do que a realidade, mesmo considerando o material já trabalhado. Na relação existem 51 espécies citadas apenas ao nível de gênero em diferentes publicações (e.g. Cliona sp., Haliclona sp., Bubaris sp.). Embora estejam computadas nesta lista como apenas um registro, é bastante provável que parte delas represente espécies diferentes. Da mesma forma, existem pelo menos outras 15 citações adicionais de exemplares com identificações preliminares, ao nível de classe, ordem ou mesmo como "unidentified sponge" (nove registros em Seleghim et al. 2007).

A produção em termos de publicações com esponjas de São Paulo mais que triplicou em relação à década anterior (Figura 1). Saltou de uma média de 2,1 para 7,2 por ano, chegando a ultrapassar dez publicações por ano em alguns períodos (2003, 2004 e 2007). Um fato interessante foi o aumento substancial no número de Dissertações e Teses. Estes trabalhos passaram de apenas um (Rocha 1993, em ecologia de costões) no período de 1990-1999 para 16 entre 2000-2009. Considerando as temáticas abordadas, tal fato sugere não apenas a formação de especialistas em taxonomia, mas também em outras áreas, como química de produtos naturais ou genética. No entanto, pode ser notado que existe uma tendência de queda nos anos mais recentes, com a média do último biênio (2008-2009) estando abaixo da registrada nos dois primeiros anos da década.

A listagem apresentada na Tabela 1 é possivelmente a maior dentre as Unidades da Federação. Em termos de biomassa, é marcante a diferença entre as Ecorregiões Sudeste (22 ${ }^{\circ} 55^{\prime}-28^{\circ} 33^{\prime} \mathrm{S}$ ) e Leste do Brasil $\left(12^{\circ} 49^{\prime}-22^{\circ} 55^{\prime} \mathrm{S}\right)$, o que pode ser constatado contrastandose os dados de Amaral et al. (2004) e Lavrado (2006). Porém esta diferença aparentemente não se mostra tão clara na riqueza de espécies. Apesar da riqueza conhecida de Porifera ser menor para a plataforma continental paulista que para a capixaba ou baiana, a riqueza total é compensada pelo grande número de espécies oriundas de costões rochosos, uma feição costeira característica da Ecorregião Sudeste do Brasil. Seus equivalentes na Ecorregião Leste do Brasil, os recifes costeiros, por um lado ainda não estão bem amostrados, e por outro, possivelmente não apresentam espongiofauna tão distinta daquela da plataforma, uma vez que neste setor a mesma é notadamente carbonática (Knoppers et al. 2009). A equivalência apontada aqui refere-se apenas à maior complexidade tridimensional conferida aos habitats marinhos consolidados e rasos.

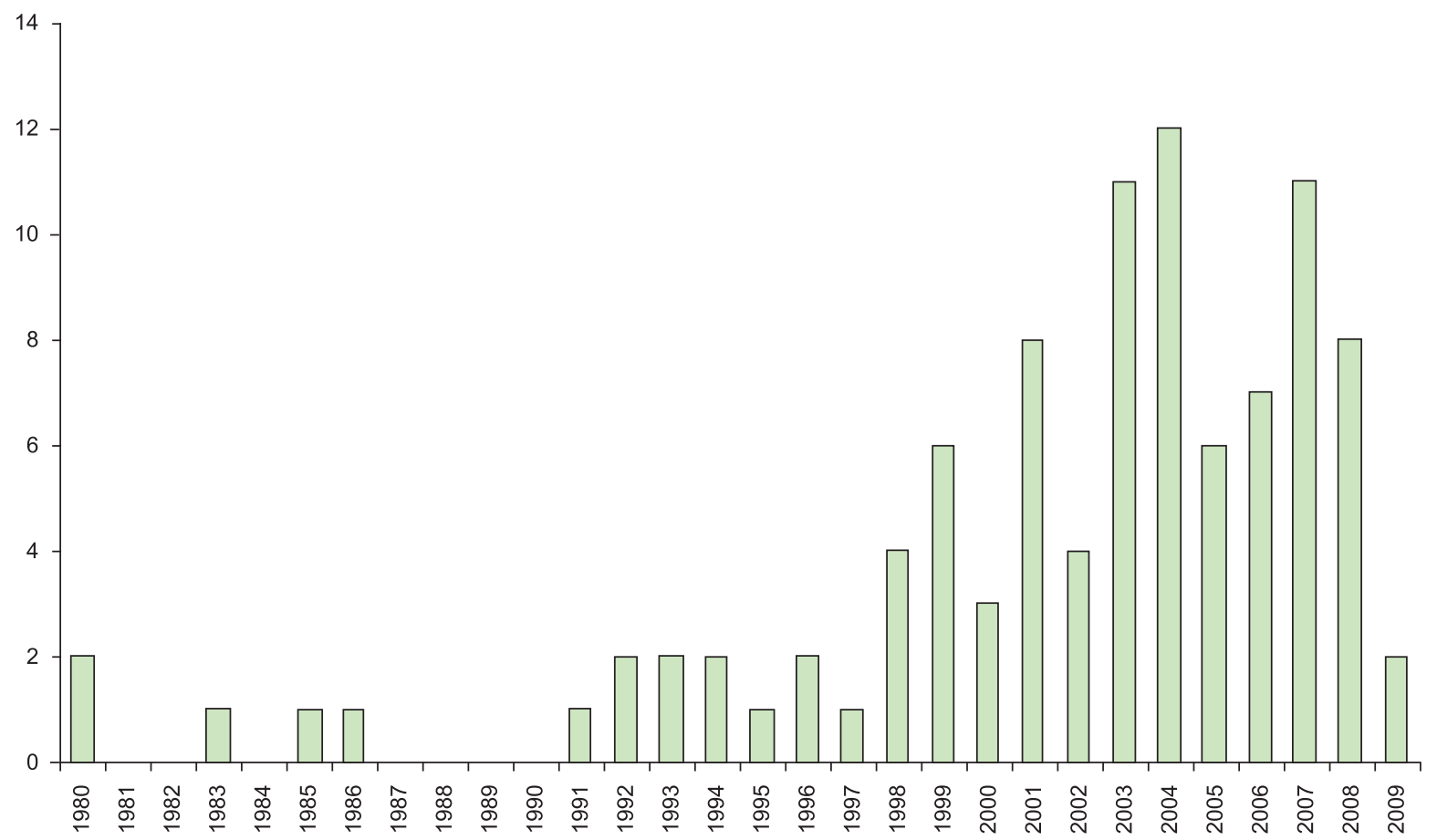

Figura 1. Número de trabalhos publicados com Porifera coletados no Estado de São Paulo no período de $1980-2009$ (incluindo Dissertações e Teses).

Figure 1. Number of publications with sponge records from São Paulo State during 1980-2009 (including Dissertations and Theses). 
Tabela 1. Classificação das esponjas marinhas e de águas continentais citadas para o Estado de São Paulo, com a localidade e profundidades de ocorrência (em metros). Table 1. Classification of marine and freshwater sponge records for São Paulo State, with locality and depth data.

\begin{tabular}{|c|c|c|c|}
\hline $\begin{array}{r}\text { Esponjas marinhas } \\
\end{array}$ & Referência(s) & Localidade(s) & Batimetria \\
\hline \multicolumn{4}{|l|}{ Classe Calcarea Bowerbank, 1864} \\
\hline \multicolumn{4}{|l|}{ Ordem Clathrinida Hartman, 1958} \\
\hline \multicolumn{4}{|l|}{ Família Clathrinidae Minchin, 1900} \\
\hline $\begin{array}{l}\text { Clathrina alcatraziensis Lanna, Rossi, } \\
\text { Cavalcanti. Hajdu \& Klautau, } 2007\end{array}$ & Lanna et al. 2007 & Alcatrazes & $8-12$ \\
\hline $\begin{array}{l}\text { Clathrina aurea Solé-Cava, Klautau, } \\
\text { Boury-Esnault, Borojevic \& Thorpe, } 1991\end{array}$ & $\begin{array}{l}\text { Lanna et al. (2007, 2009), Muricy \& } \\
\text { Hajdu (2006), Muricy et al. } 2008\end{array}$ & Canal de São Sebastião, & $1-25$ \\
\hline Clathrina conifera Klautau \& Borojevic, 2001 & Lanna et al. (2007) & Alcatrazes & 12 \\
\hline Clathrina primordialis (Haeckel, 1872) & Borojevic (1971), Mothes (1985) & Ubatuba & 20 \\
\hline Clathrina sp. & Rangel et al. (2001). Seleghim et al. (2007) & Canal de São Sebastião & $11-20$ \\
\hline Clathrina tetractina Klautau \& Borojevic, 2001 & Lanna et al. (2007) & Canal de São Sebastião & 8 \\
\hline Guancha blanca Miklucho-Maclay, 1868 & Borojevic (1971) & Ubatuba & N.D. \\
\hline \multicolumn{4}{|l|}{ Família Leucascidae Dendy, 1893} \\
\hline $\begin{array}{l}\text { Leucascus roseus Lanna, Rossi, Cavalcanti, } \\
\text { Hajdu \& Klautau, } 2007\end{array}$ & $\begin{array}{l}\text { Lanna et al. (2007), Muricy et al. (2008), } \\
\text { Lanna et al. (2009) }\end{array}$ & Alcatrazes & 14 \\
\hline \multicolumn{4}{|l|}{ Ordem Leucosolenida Hartman, 1958} \\
\hline \multicolumn{4}{|l|}{ Família Amphoriscidae Dendy, 1893} \\
\hline $\begin{array}{l}\text { Paraleucilla magna Klautau, } \\
\text { Monteiro \& Borojevic, } 2004\end{array}$ & $\begin{array}{l}\text { Klautau et al. (2004), } \\
\text { Muricy \& Hajdu (2006), Lanna (2008) }\end{array}$ & $\begin{array}{l}\text { Canal de São Sebastião, } \\
\text { Ilhabela }\end{array}$ & $1-18$ \\
\hline \multicolumn{4}{|l|}{ Família Grantiidae Dendy, 1892} \\
\hline Grantia sp. & Hajdu et al. (2004), Hajdu \& Lopes (2007) & Plataforma & $153-167$ \\
\hline \multicolumn{4}{|l|}{ Família Leucosoleniidae Minchin, 1900} \\
\hline Leucosolenia sp. & Hajdu et al. (2004), Hajdu \& Lopes (2007) & Plataforma & 380 \\
\hline \multicolumn{4}{|l|}{ Família Sycettidae Dendy, 1892} \\
\hline $\begin{array}{l}\text { Sycon pentactinalis Rossi, Farina, } \\
\text { Borojevic \& Klautau, } 2006\end{array}$ & Rossi et al. (2006) & Canal de São Sebastião & 2 \\
\hline Sycon sp. & Rocha $(1993,1995)$ & Canal de São Sebastião & $0,5-1$ \\
\hline \multicolumn{4}{|l|}{ Classe Demospongiae Grant, 1836} \\
\hline \multicolumn{4}{|l|}{ Ordem Astrophorida Sollas, 1887} \\
\hline \multicolumn{4}{|l|}{ Família Ancorinidae Schmidt, 1870} \\
\hline $\begin{array}{l}\text { Asteropus brasiliensis } \\
\text { Hajdu \& van Soest, } 1992\end{array}$ & Muricy \& Hajdu (2006), Carvalho (2008) & $\begin{array}{l}\text { Canal de São Sebastião, } \\
\text { Ilhabela, Alcatrazes }\end{array}$ & $3-100$ \\
\hline Stelletta beae Hajdu \& Carvalho, 2003 & $\begin{array}{l}\text { De Laubenfels (1956) (como Stelletta n.sp.), } \\
\text { Carvalho (2003), Hajdu \& Carvalho (2003), } \\
\text { Muricy \& Hajdu (2006) }\end{array}$ & Canal de São Sebastião & $1-2$ \\
\hline Stelletta sp. & $\begin{array}{l}\text { Hajdu et al. (1999), Rangel et al. (2001), } \\
\text { Hajdu et al. (2004), Hajdu \& Lopes (2007) }\end{array}$ & $\begin{array}{l}\text { Canal de São Sebastião, } \\
\text { Plataforma }\end{array}$ & $1-167$ \\
\hline \multicolumn{4}{|l|}{ Família Geodiidae Gray, 1867} \\
\hline Erylus soesti Mothes \& Lerner, 2001 & $\begin{array}{l}\text { Lerner (2001) (como Erylus topsenti ), } \\
\text { Mothes \& Lerner (2001) }\end{array}$ & Plataforma & 918 \\
\hline $\begin{array}{l}\text { Geodia corticostylifera Hajdu, Muricy, } \\
\text { Custódio, Russo \& Peixinho, } 1992\end{array}$ & $\begin{array}{l}\text { Hajdu et al. (1999), Rangel et al. (2001), } \\
\text { Silva (2002), Santos et al. (2003), } \\
\text { Rangel et al. (2005, 2006), Muricy \& Hajdu } \\
\text { (2006), Muricy et al. (2008), Menezes et al. } \\
\text { (2009) }\end{array}$ & $\begin{array}{l}\text { Canal de São Sebastião, } \\
\text { Ilhabela }\end{array}$ & $3-40$ \\
\hline Geodia gibberosa Lamarck, 1815 & $\begin{array}{l}\text { Lerner (2001), Rangel et al. (2001), } \\
\text { Silva (2002), Muricy \& Hajdu (2006), } \\
\text { Muricy et al. (2008) }\end{array}$ & Canal de São Sebastião & $1-20$ \\
\hline Geodia glariosa (Sollas, 1886) & $\begin{array}{l}\text { Silva (2002), Silva et al. (2007), } \\
\text { Muricy et al. (2008) }\end{array}$ & Canal de São Sebastião & $1-50$ \\
\hline Geodia papyracea (Sollas, 1886) & Silva 2002; Silva et al. 2003 & Canal de São Sebastião & $1-3$ \\
\hline Geodia sp. & $\begin{array}{l}\text { Hajdu et al. (2004), Hajdu \& Lopes (2007), } \\
\text { Seleghim et al. (2007) }\end{array}$ & $\begin{array}{l}\text { Canal de São Sebastião, } \\
\text { Plataforma }\end{array}$ & 153 \\
\hline \multicolumn{4}{|l|}{ Família Pachastrellidae Carter, 1875} \\
\hline $\begin{array}{l}\text { Characella pachastrelloides } \\
\text { (Carter, 1876) }\end{array}$ & $\begin{array}{l}\text { Hajdu et al. (2004), Hajdu \& Lopes (2007) } \\
\text { (ambos como Poecillastra sollasi) }\end{array}$ & Plataforma & 417 \\
\hline Pachastrella monilifera Schmidt, 1868 & Hajdu et al. (2004), Hajdu \& Lopes (2007) & Plataforma & 258 \\
\hline Vulcanella sp. & Hajdu et al. (2004), Hajdu \& Lopes (2007) & Plataforma & $167-380$ \\
\hline
\end{tabular}

Profundidades mínimas e máximas registradas para a costa brasileira, quando disponíveis nas publicações (N.D.: Não disponível); Esponjas identificadas ao nível de gênero em trabalhos diferentes estão computadas como apenas um registro.

Minimum and maximum depths registered for the Brazilian coast, when available in the publications (N.D.: Not available); sponges identified at the genus level in distinct publications were listed as a single record. 
Tabela 1. Continuação...

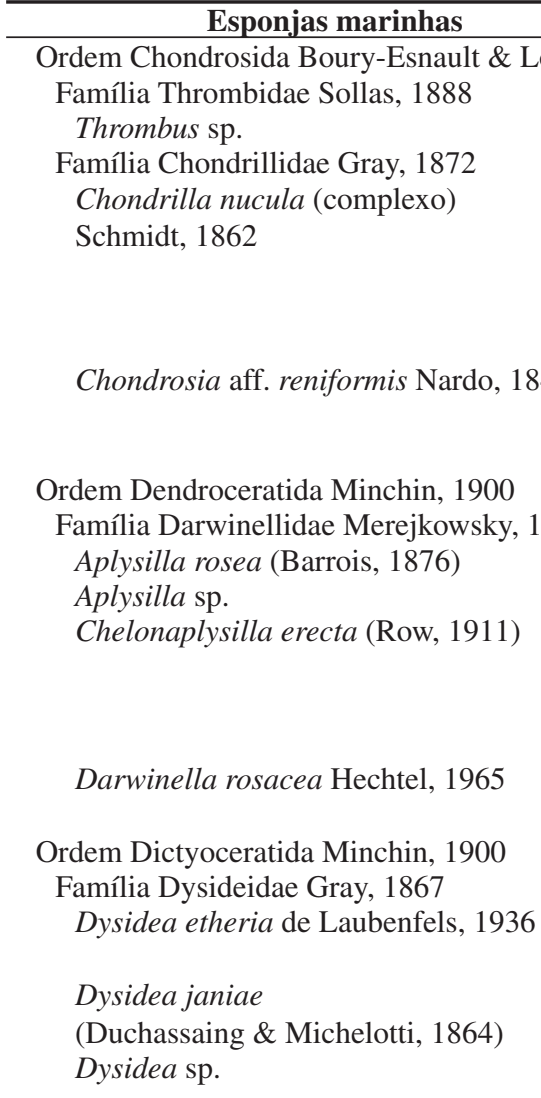

Euryspongia rosea de Laubenfels, 1936

Família Spongiidae Gray, 1867 Spongia (Heterofibria) catarinensis Mothes, Kasper, Lerner, Campos \& Carraro, 2006

Ordem Hadromerida Topsent, 1894

Família Clionaidae d'Orbigny, 1851 Cliona aff. celata Grant, 1826

Cliona dioryssa

(de Laubenfels, 1950)

Cliona sp.

Família Polymastiidae Gray, 1867

Polymastia janeirensis

(Boury-Esnault, 1973)

Polymastia sp.

Radiella sp.

Família Suberitidae Schmidt, 1870

Aaptos sp.
Referência(s)

Localidade(s)

Batimetria

Hajdu et al. (2004), Hajdu \& Lopes (2007)

Plataforma

Rocha (1993), Lerner (2001),

Rangel et al. (2001), Custódio et al. (2002),

Santos et al. (2003), Muricy \& Hajdu (2006),

Zilberberg et al. (2006) (como Chondrilla sp.

3), Muricy et al. (2008), Klautau et al. (1999)

Santos et al. (2003), Muricy \& Hajdu (2006)

(como Chondrosia sp.), Seleghim et al.

(2007) (como Chondrosia sp.)

Ubatuba, Canal de São

$0,5-30$

Sebastião, Ilhabela

Canal de São Sebastião

Muricy \& Hajdu (2006)

Rangel et al. (2001)

Hajdu et al. (1999), Rangel et al. (2001)

(como Chelonaplysilla aff. erecta),

Muricy \& Hajdu (2006), Seleghim et al.

(2007) (como Chelonaplysilla sp.)

Seleghim et al. (2007) (como Darwinella

sp.)

Canal de São Sebastião

N.D.

Canal de São Sebastião

3-8

Canal de São Sebastião, Ilhabela

$1-20$

Canal de São Sebastião

N.D.

Vilanova (2003), Muricy \& Hajdu (2006)

Vilanova (2003)

Canal de São Sebastião, Ilhabela

Canal de São Sebastião

$1-18$

Seleghim et al. (2007), Shimabukuro (2007)

Canal de São Sebastião,

N.D.

Vilanova (2003)

Alcatrazes

Alcatrazes

6-12

Seleghim et al. (2007) (como Spongia sp.)

Canal de São Sebastião

N.D.

Boury-Esnault (1973), Mothes (1985)

(ambas como Cliona celata), Lerner (2001),

Lôbo-Hajdu et al. (2003), Santos et al. (2003),

Muricy \& Hajdu (2006),

Hajdu \& Lopes (2007), Muricy et al. (2008)

(como Cliona celata)

Muricy \& Hajdu (2006)

Hajdu et al. (2004), Hajdu \& Lopes (2007),

Seleghim et al. (2007), Shimabukuro (2007)

Boury-Esnault et al. (1994),

Lerner (2001), Santos et al. (2003),

Muricy \& Hajdu (2006), Seleghim et al.

(2007) (como Polymastia sp.)

Hajdu et al. (2004), Hajdu \& Lopes (2007)

Sumida et al. (2004)

Canal de São Sebastião,

$1-100$

Plataforma

(off Ilhabela)

Canal de São Sebastião, Ilhabela

Canal de São Sebastião, Plataforma

Canal de São Sebastião

Plataforma

168

Plataforma

700

(off Cananéia)

Granato et al. (2000), Rangel et al. (2001),

Canal de São Sebastião

$1-15$

Muricy \& Hajdu (2006),

Seleghim et al. (2007)

Profundidades mínimas e máximas registradas para a costa brasileira, quando disponíveis nas publicações (N.D.: Não disponível); Esponjas identificadas ao nível de gênero em trabalhos diferentes estão computadas como apenas um registro.

Minimum and maximum depths registered for the Brazilian coast, when available in the publications (N.D.: Not available); sponges identified at the genus level in distinct publications were listed as a single record. 
Tabela 1. Continuação...

\begin{tabular}{|c|c|c|c|}
\hline Esponjas marinhas & Referência(s) & Localidade(s) & Batimetria \\
\hline $\begin{array}{l}\text { Suberites aurantiacus } \\
\text { (Duchassaing \& Michelotti, 1864) }\end{array}$ & $\begin{array}{l}\text { Santos et al. (2003) (como Protosuberites } \\
\text { aurantiacus), Muricy \& Hajdu (2006) }\end{array}$ & Canal de São Sebastião & $1-15$ \\
\hline $\begin{array}{l}\text { Suberites caminatus } \\
\text { Ridley \& Dendy, } 1886\end{array}$ & Boury-Esnault (1973) & $\begin{array}{l}\text { Plataforma } \\
\text { (off Ubatuba) }\end{array}$ & 46 \\
\hline Terpios fugax Duchassaing \& Michelotti, 1864 & Muricy \& Hajdu (2006) & Canal de São Sebastião & $1-15$ \\
\hline $\begin{array}{l}\text { Terpios sp. } \\
\text { Família Tethyidae Grav, } 1848\end{array}$ & Seleghim et al. (2007) & Canal de São Sebastião & N.D. \\
\hline $\begin{array}{l}\text { Halicometes minuta Sarà \& de Rosa-Barbosa, } 1995 \\
\text { Tethya diploderma Schmidt, } 1870 \\
\text { Tethya maza } \text { Selenka, } 1879\end{array}$ & $\begin{array}{l}\text { Hajdu et al. (2004), Hajdu \& Lopes (2007) } \\
\text { Lerner (2001) } \\
\text { Mothes (1980), Lerner (2001) }\end{array}$ & $\begin{array}{c}\text { Plataforma } \\
\text { São Paulo (citação) } \\
\text { Canal de São Sebastião }\end{array}$ & $\begin{array}{l}133-153 \\
\text { N.D. } \\
2-3\end{array}$ \\
\hline \multicolumn{4}{|l|}{ Família Timeidae Gray, 1848} \\
\hline Timea authia de Laubenfels, 1930 & Lerner (2001) & São Paulo (citação) & N.D. \\
\hline Timea n.sp. 1 & Santos (2004) (como “Timea brasiliensis") & $\begin{array}{l}\text { Canal de São Sebastião, } \\
\text { Ilhabela }\end{array}$ & $3-15$ \\
\hline Timea n.sp. 2 & Santos (2004) (como “Timea garoupai”) & $\begin{array}{l}\text { Plataforma } \\
\text { (off Ilhabela) }\end{array}$ & $50-147$ \\
\hline Timea n.sp. 3 & Santos (2004) (como “Timea magnisphaera”) & Ubatuba & $7-20$ \\
\hline Timea n.sp. 4 & Santos (2004) (como "Timea quadriradiata)" & Canal de São Sebastião & 15 \\
\hline Timea n.sp. 5 & $\begin{array}{l}\text { Santos (2004) } \\
\text { (como "Timea sulcata") }\end{array}$ & $\begin{array}{l}\text { Canal de São Sebastião, } \\
\text { Ilhabela }\end{array}$ & $5-26$ \\
\hline Timea n.sp. 6 & $\begin{array}{l}\text { Santos (2004) } \\
\text { (como "Timea verrucosa”) }\end{array}$ & $\begin{array}{l}\text { Canal de São Sebastião, } \\
\text { Ilhabela }\end{array}$ & $2-17$ \\
\hline Timea sp. & $\begin{array}{l}\text { Hajdu et al. (2004), Mothes et al. (2004), } \\
\text { Hajdu \& Lopes (2007) }\end{array}$ & Plataforma & 147 \\
\hline \multicolumn{4}{|l|}{ Família Trachycladidae Hallmann, 1917} \\
\hline $\begin{array}{l}\text { Trachycladus sp. } \\
\text { Ordem Halichondrida Gray, } 1867 \\
\text { Família Axinellidae Carter, } 1875\end{array}$ & Seleghim et al. (2007) & Canal de São Sebastião & N.D. \\
\hline Axinella corrugata (George \& Wilson, 1919) & $\begin{array}{l}\text { Hajdu et al. (1999), Rangel et al. (2001), } \\
\text { Santos et al. (2003) (todas três como } \\
\text { Axinella aff. corrugata), Carvalho (2003), } \\
\text { Muricy \& Hajdu (2006), Lira (2007), } \\
\text { Lira et al. (2007) } \\
\text { (como Axinella aff. corrugata), } \\
\text { Seleghim et al. (2007) (como Axinella sp.), } \\
\text { Milanetto (2008), Menezes et al. (2009) }\end{array}$ & $\begin{array}{c}\text { Canal de São Sebastião, } \\
\text { Ilhabela }\end{array}$ & $2-17$ \\
\hline $\begin{array}{l}\text { Dragmacidon reticulatum } \\
\text { (Ridley \& Dendy, 1886) }\end{array}$ & $\begin{array}{l}\text { Hajdu et al. (1999) (como Pseudaxinella } \\
\text { reticulata), Lôbo-Hajdu et al. (1999), Lerner } \\
2001 \text { (como Pseudaxinella reticulata), } \\
\text { Carvalho (2003), Lôbo-Hajdu et al. (2003), } \\
\text { Santos et al. (2003), Muricy \& Hajdu (2006) } \\
\text { (as quatro como Dragmacidon reticulatus), } \\
\text { Seleghim et al. (2007) (como Dragmacidon } \\
\text { sp.), Menezes et al. (2009) (como } \\
\text { Dragmacidon reticulata). }\end{array}$ & $\begin{array}{l}\text { Ubatuba, Canal de São } \\
\text { Sebastião, Alcatrazes }\end{array}$ & $1-24$ \\
\hline $\begin{array}{l}\text { Dragmaxia anomala } \\
\text { Carvalho \& Hajdu, } 2004\end{array}$ & $\begin{array}{l}\text { Carvalho (2003), } \\
\text { Carvalho \& Hajdu (2004) }\end{array}$ & $\begin{array}{l}\text { Canal de São Sebastião, } \\
\text { Ilhabela }\end{array}$ & $13-20$ \\
\hline $\begin{array}{l}\text { Ptilocaulis marquezi } \\
\text { (Duchassaing \& Michelotti, 1864) }\end{array}$ & Carvalho (2003) & Canal de São Sebastião & 2 \\
\hline $\begin{array}{l}\text { Família Bubaridae Topsent, } 1894 \\
\text { Bubaris sp. }\end{array}$ & $\begin{array}{l}\text { Hajdu et al. (2004), Mothes et al. (2004), } \\
\text { Hajdu \& Lopes (2007) }\end{array}$ & Plataforma & 153 \\
\hline $\begin{array}{l}\text { Família Dictyonellidae Van Soest, Diaz \& Pomp } \\
\text { Scopalina ruetzleri } \\
\text { (Wiedenmayer, 1977) }\end{array}$ & $\begin{array}{l}\text { oni, } 1990 \\
\text { Hajdu et al. (1999), Carvalho (2003), } \\
\text { Santos et al. (2003), } \\
\text { Muricy \& Hajdu (2006), Seleghim et al. } \\
\text { (2007) (como Scopalina sp.) }\end{array}$ & $\begin{array}{c}\text { Ubatuba, } \\
\text { Canal de São Sebastião }\end{array}$ & $1-15$ \\
\hline Scopalina hispida Hechtel, 1965 & Carvalho (2003) & Ilhabela & $8-22$ \\
\hline
\end{tabular}

\footnotetext{
Profundidades mínimas e máximas registradas para a costa brasileira, quando disponíveis nas publicações (N.D.: Não disponível); Esponjas identificadas ao nível de gênero em trabalhos diferentes estão computadas como apenas um registro.

Minimum and maximum depths registered for the Brazilian coast, when available in the publications (N.D.: Not available); sponges identified at the genus level in distinct publications were listed as a single record.
} 
Tabela 1. Continuação...

\begin{tabular}{|c|c|c|c|}
\hline $\begin{array}{c}\text { Esponjas marinhas } \\
\end{array}$ & Referência(s) & Localidade(s) & Batimetria \\
\hline Família Heteroxyidae Dendy, 1905 & & & \\
\hline Higginsia strigilata (Lamarck, 1813) & Carvalho (2003) & Canal de São Sebastião & N.D. \\
\hline \multicolumn{4}{|l|}{ Família Halichondriidae Gray, 1867} \\
\hline Amorphinopsis atlantica & Hajdu et al. (1999), Rangel et al. (2001) & \multirow{2}{*}{$\begin{array}{c}\text { Canal de São Sebastião, } \\
\text { Ilhabela }\end{array}$} & \multirow[t]{2}{*}{$1-16$} \\
\hline Carvalho, Hajdu, Mothes \& van Soest, 2004 & $\begin{array}{l}\text { (ambas como Amorphinopsis sp.), } \\
\text { Carvalho (2003), Carvalho et al. (2004), } \\
\text { Muricy \& Hajdu (2006) }\end{array}$ & & \\
\hline $\begin{array}{l}\text { Ciocalypta alba Carvalho, Carraro, } \\
\text { Lerner \& Hajdu, } 2003\end{array}$ & $\begin{array}{l}\text { Rangel et al. (2001) (Ciocalypta sp.), } \\
\text { Carvalho (2003), Carvalho et al. (2003), } \\
\text { Santos et al. (2003) }\end{array}$ & $\begin{array}{c}\text { Canal de São Sebastião, } \\
\text { Ilhabela }\end{array}$ & $12-25$ \\
\hline Halichondria (Halichondria) cebimarensis & Carvalho \& Hajdu (2001), Lerner (2001), & \multirow[t]{2}{*}{ Canal de São Sebastião } & \multirow[t]{2}{*}{$1-2$} \\
\hline Carvalho \& Hajdu, 2001 & $\begin{array}{l}\text { Carvalho (2003), Santos et al. (2003), } \\
\text { Muricy \& Hajdu (2006) }\end{array}$ & & \\
\hline Halichondria (Halichondria) migottea & Carvalho \& Hajdu (2001), Lerner (2001), & \multirow[t]{2}{*}{ Canal de São Sebastião } & \multirow[t]{2}{*}{$1-2$} \\
\hline Carvalho \& Hajdu, 2001 & Carvalho (2003) & & \\
\hline Halichondria (Halichondria) sulfurea & Duarte (1980) (como Halichondria & \multirow{2}{*}{$\begin{array}{l}\text { Ubatuba, Canal de São } \\
\text { Sebastião, Ilhabela }\end{array}$} & \multirow[t]{2}{*}{$0,5-1$} \\
\hline Carvalho \& Hajdu, 2001 & $\begin{array}{l}\text { magniconulosa), Carvalho \& Hajdu (2001), } \\
\text { Lerner (2001) (como Halichondria } \\
\text { magniconulosa), Carvalho (2003) }\end{array}$ & & \\
\hline $\begin{array}{l}\text { Halichondria (Halichondria) tenebrica } \\
\text { Carvalho \& Hajdu, } 2001\end{array}$ & $\begin{array}{l}\text { Carvalho \& Hajdu (2001), Lerner (2001), } \\
\text { Carvalho (2003) }\end{array}$ & Canal de São Sebastião & $0,5-2$ \\
\hline Halichondria sp. & Hajdu et al. (2004), Hajdu \& Lopes (2007) & Plataforma & 153 \\
\hline \multirow[t]{8}{*}{ Hymeniacidon heliophila (Parker, 1910) } & Lôbo-Hajdu et al. (1999), & \multirow[t]{8}{*}{ Canal de São Sebastião } & \multirow[t]{8}{*}{$0,5-15$} \\
\hline & Granato et al. (2000) (como Hymeniacidon & & \\
\hline & aff. heliophila), Lerner (2001), Rangel et al. & & \\
\hline & (2001) (como Hymeniacidon aff. heliophila), & & \\
\hline & Carvalho (2003), Lôbo-Hajdu et al. (2003), & & \\
\hline & Santos et al. (2003), Berlinck et al. (2004), & & \\
\hline & Custódio et al. (2004), Oliveira (2004), & & \\
\hline & Muricy \& Hajdu (2006), Seleghim et al. & & \\
\hline Topsentia sp. & Hajdu et al. (2004), Hajdu \& Lopes (2007) & Plataforma & 147 \\
\hline \multicolumn{4}{|l|}{ Ordem Haplosclerida Topsent, 1928} \\
\hline \multicolumn{4}{|l|}{ Família Callyspongiidae de Laubenfels, 1936} \\
\hline Callyspongia pallida Hechtel, 1965 & Muricy \& Hajdu (2006) & $\begin{array}{l}\text { Canal de São Sebastião, } \\
\text { Ilhabela }\end{array}$ & N.D. \\
\hline \multirow[t]{3}{*}{ Callyspongia sp. } & Rocha (1993), Rangel et al. (2001), & \multirow[t]{3}{*}{ Canal de São Sebastião } & \multirow[t]{3}{*}{$0,5-21$} \\
\hline & Gray et al. (2006), Lira (2007), & & \\
\hline & Seleghim et al. (2007) & & \\
\hline \multicolumn{4}{|l|}{ Família Chalinidae Gray, 1867} \\
\hline Haliclona (Haliclona) sp. & Rocha (1993) (como Adocia sp.) & Canal de São Sebastião & $0,5-1$ \\
\hline Haliclona (Reniera) sp. & Rocha (1993) (como Reniera sp.) & Canal de São Sebastião & $0,5-1$ \\
\hline $\begin{array}{l}\text { Haliclona (Reniera) tubifera } \\
\text { (George \& Wilson, 1919) }\end{array}$ & Lerner (2001) & São Paulo (citação) & N.D. \\
\hline Haliclona (Soestella) melana & Muricy \& Ribeiro (1999), & \multirow{2}{*}{$\begin{array}{c}\text { Canal de São Sebastião, } \\
\text { Ilhabela }\end{array}$} & \multirow[t]{2}{*}{$1-6$} \\
\hline Muricy \& Ribeiro, 1999 & $\begin{array}{l}\text { Custódio et al. (2002), Santos et al. (2003), } \\
\text { Muricy \& Hajdu (2006) }\end{array}$ & & \\
\hline Haliclona sp. & $\begin{array}{l}\text { Hajdu et al. (1999), Hajdu \& Lopes (2007), } \\
\text { Seleghim et al. (2007) }\end{array}$ & $\begin{array}{c}\text { Canal de São Sebastião, } \\
\text { Plataforma }\end{array}$ & 380 \\
\hline \multicolumn{4}{|l|}{ Família Niphatidae van Soest, 1980} \\
\hline $\begin{array}{l}\text { Amphimedon erina } \\
\text { (de Laubenfels, 1936) }\end{array}$ & $\begin{array}{l}\text { Duarte (1980) (como Haliclona erina), } \\
\text { Lerner (2001) }\end{array}$ & Ubatuba & N.D. \\
\hline
\end{tabular}

Profundidades mínimas e máximas registradas para a costa brasileira, quando disponíveis nas publicações (N.D.: Não disponível); Esponjas identificadas ao nível de gênero em trabalhos diferentes estão computadas como apenas um registro.

Minimum and maximum depths registered for the Brazilian coast, when available in the publications (N.D.: Not available); sponges identified at the genus level in distinct publications were listed as a single record. 
Tabela 1. Continuação...

\begin{tabular}{|c|c|}
\hline Esponjas marinhas & Referência(s) \\
\hline Amphimedon viridis & Rocha (1993), Berlinck et al. (1996), \\
\hline Duchassaing \& Michelotti, 1864 & $\begin{array}{l}\text { Chehade et al. (1997), Hajdu et al. (1999), } \\
\text { Muricy \& Ribeiro (1999), } \\
\text { Custódio et al. (2002), Santos et al. (2003), } \\
\text { Pinheiro et al. (2005), } \\
\text { Muricy \& Hajdu (2006), Prado (2007), } \\
\text { Seleghim et al. (2007) (como Amphimedon sp., } \\
\text { Majer (2008), Menezes et al. (2009) }\end{array}$ \\
\hline Pachychalina alcaloidifera & Rangel et al. (2001) (como \\
\hline Pinheiro, Berlinck \& Hajdu, 2005 & $\begin{array}{l}\text { Amphimedon sp.), Pinheiro et al. (2005), } \\
\text { Seleghim et al. (2007) } \\
\text { (como Pachychalina sp.) }\end{array}$ \\
\hline $\begin{array}{l}\text { Família Petrosiidae Van Soest, } 1980 \\
\text { Neopetrosia carbonaria } \\
\text { (Lamarck, 1814) }\end{array}$ & $\begin{array}{l}\text { Rocha }(1993,1995) \text { (ambas como } \\
\text { Adocia carbonaria), Carvalho (2003) } \\
\text { (como Xestospongia cf. carbonaria) }\end{array}$ \\
\hline $\begin{array}{l}\text { Família Phloeodictyidae Carter, } 1882 \\
\text { Oceanapia nodosa } \\
\text { (George \& Wilson, 1919) }\end{array}$ & $\begin{array}{l}\text { Hajdu et al. (1999), Muricy \& Ribeiro } \\
\text { (1999), Rangel et al. (2001), } \\
\text { Muricy \& Hajdu (2006), Seleghim et al. } \\
\text { (2007) (como Oceanapia sp.) }\end{array}$ \\
\hline $\begin{array}{l}\text { Pachypellina sp. } \\
\text { Ordem Lithistida Schmidt, } 1870\end{array}$ & Hajdu et al. (2004), Hajdu \& Lopes (2007) \\
\hline $\begin{array}{l}\text { Família Desmanthidae Topsent, } 1894 \\
\text { Desmanthus meandroides van Soest \& Hajdu, } \\
2000 \\
\text { Petromica (Chaladesma) citrina Muricy, } \\
\text { Hajdu, Minervino, Madeira \& Peixinho, } 2001\end{array}$ & $\begin{array}{l}\text { Lerner (2001), van Soest \& Hajdu (2000), } \\
\text { Muricy \& Hajdu (2006) } \\
\text { Hajdu et al. (1999) (como Petromica } \\
\text { sp.), Lerner (2001), Muricy et al. (2001), } \\
\text { Rangel et al. (2001) (como Petromica sp.), } \\
\text { Carvalho (2003), Santos et al. (2003), } \\
\text { Muricy \& Hajdu (2006), Seleghim et al. } \\
\text { (2007) (como Petromica sp.) }\end{array}$ \\
\hline
\end{tabular}

Gastrophanella sp.

Ordem Poecilosclerida Topsent, 1928

Família Coelosphaeridae Dendy, 1922

Forcepia sp.

Lissodendoryx (Lissodendoryx) isodictyalis

(Carter, 1882)

Lissodendoryx sp.

Família Crambeidae Lévi, 1963

Monanchora arbuscula

(Duchassaing \& Michelotti, 1864)

Família Crellidae Dendy, 1922

Crella (Yvesia) sp.

Família Desmacellidae Ridley \& Dendy, 1886

Desmacella aff. pumilio Schmidt, 1870

Desmacella annexa Schmidt, 1870

Desmacella sp.

Família Esperiopsidae Hentschel, 1923

Esperiopsis bathyalis

Lopes \& Hajdu, 2004

Família Guitarridae Dendy, 1924

Guitarra sepia Lerner, Hajdu,

Custódio \& van Soest, 2004

Família Hamacanthidae Gray, 1872

Hamacantha (Hamacantha) microxifera

Lopes \& Hajdu, 2004

Hamacantha sp. 2

$\begin{array}{cc}\text { Localidade(s) } & \text { Batimetria } \\ \begin{array}{c}\text { Canal de São Sebastião, } \\ \text { Ilhabela, Ubatuba }\end{array} & 0,5-8\end{array}$

Ubatuba, Canal de São

Sebastião, Ilhabela

Canal de São Sebastião

Canal de São Sebastião, Ilhabela

Plataforma

Canal de São Sebastião, Ilhabela

Canal de São Sebastião, Ilhabela

Plataforma

167

Hajdu et al. (2004), Hajdu \& Lopes (2007)

Lerner (2001)

Hajdu et al. (2004), Hajdu \& Lopes (2007)

Muricy \& Hajdu (2006)

Plataforma

258

São Paulo (citação)

N.D.

Plataforma

Canal de São Sebastião, Ilhabela

Hajdu et al. (2004), Hajdu \& Lopes (2007)

Hajdu et al. (2004), Hajdu \& Lopes (2007)

Hajdu et al. (2004), Hajdu \& Lopes (2007)

Hajdu et al. (2004), Hajdu \& Lopes (2007)

Hajdu et al. (2004),

Hajdu \& Lopes (2007)

Plataforma

380

Plataforma

133

Plataforma

153-167

Plataforma

Plataforma

808

(off Guarujá)

Rangel et al. (2001) (como Guitarridae sp.), Lerner et al. (2003), Seleghim et al. (2007) (como Guitarra sp.)

Lopes \& Hajdu (2004),

Plataforma

(off Guarujá)

Hajdu \& Lopes (2007)

Plataforma

166

anal de São Sebastião, ao nível de gênero em trabalhos diferentes estão computadas como apenas um registro.

Minimum and maximum depths registered for the Brazilian coast, when available in the publications (N.D.: Not available); sponges identified at the genus level in distinct publications were listed as a single record. 
Tabela 1. Continuação...

\begin{tabular}{l} 
Esponjas marinhas \\
\hline Hamacantha sp. 3 \\
Família Latrunculiidae Topsent, 1922 \\
Sceptrella sp. \\
Família Microcionidae Carter, 1875 \\
Artemisina aff. melana van Soest, 1 \\
Clathria (Microciona) campecheae \\
Hooper, 1996 \\
Clathria sp. \\
Família Mycalidae Lundbeck, 1905 \\
Mycale (Aegogropila) americana \\
van Soest, 1984
\end{tabular}

Mycale (Aegogropila) escarlatei Hajdu, Zea,

Mycale (Aegogropila) lilianae

Carballo \& Hajdu, 1998

(Duchassaing \& Michelotti, 1864)

Mycale (Carmia) magnirhaphidifera

Mycale (Carmia) microsigmatosa
Arndt, 1927

Mycale (Mycale) beatrizae

Hajdu \& Desqueyroux-Faúndez, 1994

Mycale (Naviculina) arcuiris

Lerner \& Hajdu, 2002

Mycale (Naviculina) purpurata

Lerner \& Hajdu, 2002

Mycale (Zygomycale) angulosa

(Duchassaing \& Michelotti, 1864)

Mycale sp.

Família Myxillidae Dendy, 1922

Myxilla (Ectyomyxilla) chilensis

Thiele, 1905 Kielman \& Peixinho, 1995

Mycale (Arenochalina) laxissima van Soest, 1984

\begin{tabular}{|c|c|c|}
\hline Referência(s) & Localidade(s) & Batimetria \\
\hline Hajdu et al. (2004), Hajdu \& Lopes (2007) & Plataforma & 167 \\
\hline Hajdu et al. (2004), Hajdu \& Lopes (2007) & Plataforma & 167 \\
\hline Rocha (1993) & Canal de São Sebastião & $0,5-1$ \\
\hline $\begin{array}{l}\text { Rocha (1993) (como Clathria sp.), } \\
\text { Santos et al. (2003), Muricy \& Hajdu (2006) }\end{array}$ & $\begin{array}{c}\text { Canal de São Sebastião, } \\
\text { Ilhabela }\end{array}$ & $0,5-15$ \\
\hline $\begin{array}{l}\text { Hajdu \& Lopes (2007), } \\
\text { Seleghim et al. (2007) }\end{array}$ & $\begin{array}{c}\text { Canal de São Sebastião, } \\
\text { Plataforma }\end{array}$ & 157 \\
\hline $\begin{array}{l}\text { Rocha (1993), Lôbo-Hajdu et al. (1999), } \\
\text { Rangel et al. (2001) (como Mycale aff. }\end{array}$ & $\begin{array}{c}\text { Canal de São Sebastião, } \\
\text { Ilhabela }\end{array}$ & $0,5-15$ \\
\hline
\end{tabular}

americana), Lôbo-Hajdu et al. (2003),

Santos et al. (2003) (ambas como Mycale

aff. americana), Muricy \& Hajdu (2006)

Lôbo-Hajdu et al. (1999, 2003),

Muricy \& Hajdu (2006)

Carballo \& Hajdu (1998),

Lerner (2001)

Hajdu et al. (1999), Lôbo-Hajdu et al.

(1999), Lerner (2001), Rangel et al. (2001),

Custódio et al. (2002), Lôbo-Hajdu et al.

(2003), Santos et al. (2003), Muricy \&

Hajdu (2006), Menezes et al. (2009)

Carballo \& Hajdu (2001),

Lôbo-Hajdu et al. (2003),

Santos et al. (2003), Lerner et al. (2005),

Muricy \& Hajdu (2006),

Shimabukuro (2007)

Hajdu \& Boury-Esnault (1991),

Rocha (1993), Hajdu et al. (1999),

Lôbo-Hajdu et al. (1999), Lerner (2001),

Rangel et al. (2001), Custódio et al. (2002),

Lôbo-Hajdu et al. (2003),

Muricy \& Hajdu (2006), Shimabukuro (2007)

Hajdu \& Desqueyroux-Faúndez (1994),

Hajdu \& Lopes (2007)

Lerner (2001), Lerner \& Hajdu (2002),

Lôbo-Hajdu et al. (2003)

Lerner (2001),

Lerner \& Hajdu (2002)

Duarte (1980), Duarte \& Morgado (1983),

Duarte \& Nalesso (1996) (todas como

Zygomycale parishii), Hajdu et al. (1999),

Lôbo-Hajdu et al. (1999), Lerner (2001),

Custódio et al. (2002), Santos et al. (2003),

Muricy \& Hajdu (2006), Shimabukuro

(2007), Majer (2008), Muricy et al. (2008),

Menezes et al. (2009)

Hajdu et al. (1999), Seleghim et al. (2007)

Boury-Esnault (1973) (como Ectyomyxilla

kerguelenensis), Lerner (2001)

(como Ectyomyxilla chilensis),

Carvalho (2003), Hajdu \& Lopes 2007

(ambas como Crellomyxilla chilensis)

Myxilla (Myxilla) mucronata Pulitzer-Finali, 1986 Rocha 1993; Muricy \& Hajdu 2006

Hymenancora tenuissima

Hajdu et al. (2004), Hajdu \& Lopes (2007)

(ambas como Mvxilla (Mvxilla) tenuissima)

Canal de São Sebastião, 2-20 Ilhabela Ubatuba,

Canal de São Sebastião

Canal de São Sebastião, Ilhabela

Ubatuba,

Canal de São Sebastião

Canal de São Sebastião,

$0,5-12$ Ilhabela
Plataforma
(off Ubatuba)

Canal de São Sebastião, Ilhabela

Canal de São Sebastião, Ilhabela

Ubatuba, Canal de São

Sebastião, Ilhabela, Guarujá
Canal de São Sebastião

N.D.

136-167

1-18

Plataforma

(off Ilhabela)

Canal de São Sebastião

0,5-3 Plataforma

Profundidades mínimas e máximas registradas para a costa brasileira, quando disponíveis nas publicações (N.D.: Não disponível); Esponjas identificadas ao nível de gênero em trabalhos diferentes estão computadas como apenas um registro.

Minimum and maximum depths registered for the Brazilian coast, when available in the publications (N.D.: Not available); sponges identified at the genus level in distinct publications were listed as a single record. 
Tabela 1. Continuação...

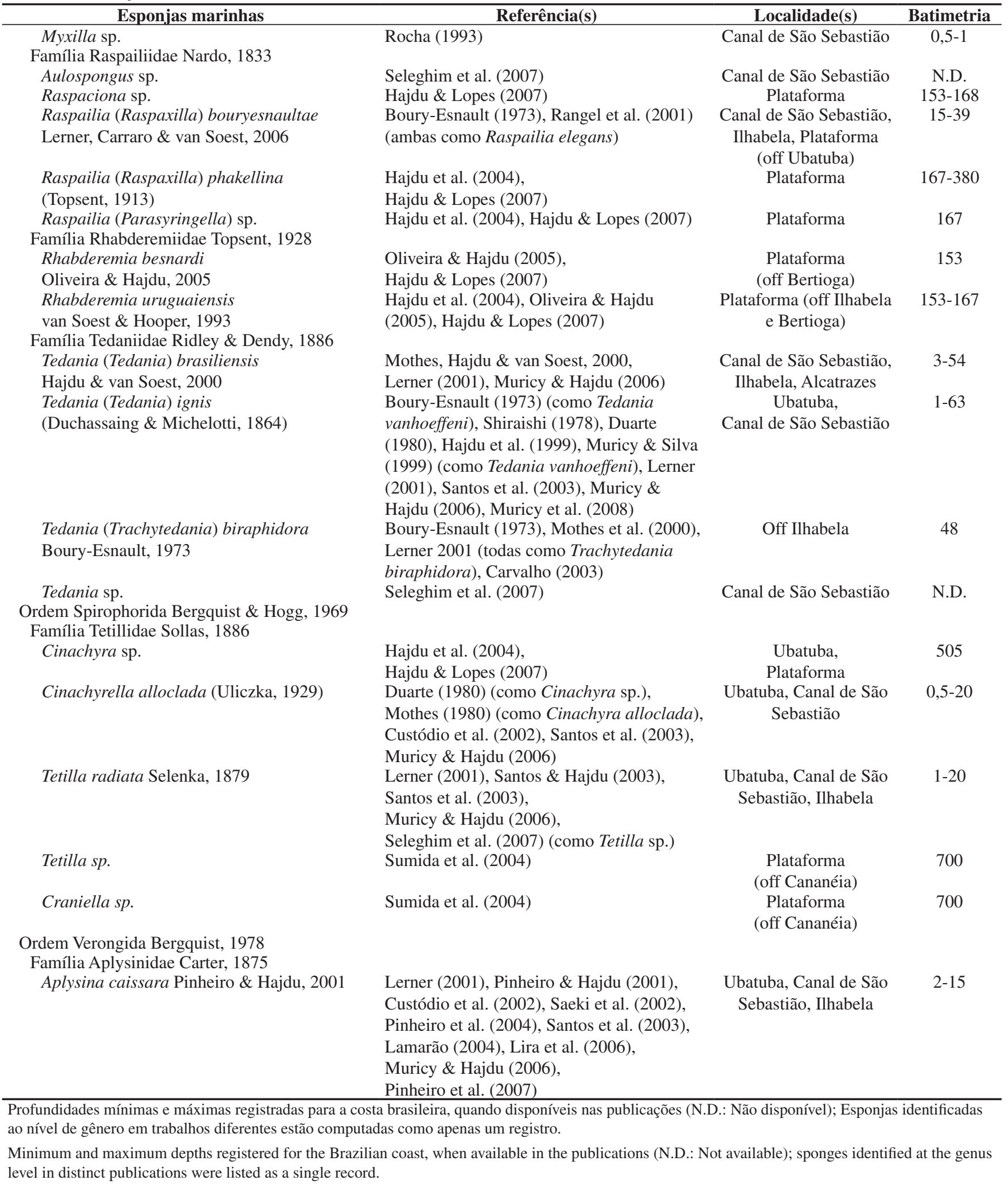


Tabela 1. Continuação...

\begin{tabular}{clc}
\hline Esponjas marinhas & \multicolumn{1}{c}{ Referência(s) } & \multicolumn{1}{c}{ Localidade(s) } \\
\hline Aplysina fulva (Pallas, 1766) & $\begin{array}{l}\text { Lerner (2001), Pinheiro \& Hajdu (2001) } \\
\text { (ambas como Aplysina cauliformis), }\end{array}$ & Canal de São Sebastião \\
& Pinheiro et al. (2004), Santos et al. & \\
& (2003), Lamarão (2004) (como Aplysina & \\
& cauliformis), Muricy \& Hajdu (2006), & \\
& Pereira (2006), Muricy et al. (2007), (como & \\
& Aplysina cauliformis), Pinheiro et al. (2007), & \\
& Nunez et al. (2008), Muricy et al. (2008) & Canal de São Sebastião \\
(como Aplysina cauliformis) & N.D. \\
Aplysina sp. & Seleghim et al. (2007) & Plataforma \\
Classe Hexactinellida Schmidt, 1870 & & (off Cananéia) \\
Ordem Amphidiscosida Schrammen, 1924 & & 700 \\
Família Hyalonematidae Gray, 1857 & Sumida et al. (2004) & \\
Hyalonema sp. & &
\end{tabular}

\section{Esponjas de águas continentais \\ Classe Demospongiae Grant, 1836 \\ Ordem Haplosclerida Topsent, 1928 \\ Família Metaniidae Volkmer-Ribeiro, 1986 \\ Corvomeyenia thumi (Traxler, 1895)}

Drulia uruguayensis

Bonetto \& Ezcurra de Drago, 1969

Metania spinata Carter, 1881

Família Potamolepidae Brien, 1967

Oncosclera navicella (Carter, 1881)

Sterrastrolepis brasiliensis

Volkmer-Ribeiro \& de Rosa Barbosa, 1978

Uruguaya corallioides

(Bowerbank, 1863)

Família Spongillidae Gray, 1867

Corvospongilla seckti

Bonetto \& Ezcurra de Drago, 1966

Dosilia pydanieli Volkmer-Ribeiro, 1992

Eunapius fragilis (Leidy, 1851)

Radiospongilla amazonensis

Volkmer-Ribeiro \& Maciel, 1993

Trochospongilla repens (Hinde, 1888)

Trochospongilla variabilis

Bonetto \& Ezcurra de Drago, 1973

\section{Outros registros}

Astrophorida sp.

Axinellidae sp.

Calcarea sp.

Hadromerida sp.

Haplosclerida sp.

Keratosa sp.

Unidentified sponges ( 9 registros)
Volkmer-Ribeiro (1999), Pinheiro et al.

(2003)

Fusari et al. (2008)

Volkmer-Ribeiro (1979, 1986), VolkmerRibeiro \& Costa (1992), Volkmer-Ribeiro \& Tavares (1993), Melão \& Rocha (1996a, b, c, d, 1997, 1998), Melão (1999), Silva \& Volkmer-Ribeiro (1998), Volkmer-Ribeiro (1999), Pinheiro et al. (2003), Roque et al. (2004), Pinheiro (2007), Gorni \& Alves (2008)

Pinheiro et al. (2003), Roque et al. (2004, 2005), Pinheiro (2007), Fusari et al. (2008) Pinheiro (2007)

Pinheiro et al. (2003), Pinheiro (2007),

Fusari et al. (2008)

Pinheiro et al. (2003), Roque et al. (2004, 2005), Pinheiro (2007),Fusari et al. (2008) Volkmer-Ribeiro (1999), Pinheiro et al. (2003)

Volkmer-Ribeiro (1999), Pinheiro et al. (2003)

Carvalho (1942) (como Ephydatia

crateriformis), Volkmer-Ribeiro (1999),

Pinheiro et al. (2003), Corbi et al. (2005),

Pinheiro (2007)

Fusari et al. (2008)

Volkmer-Ribeiro (1999),

Pinheiro et al. (2003) (off Cananéia)

$\begin{array}{cc}\text { São Paulo (citação) } & \text { N.D. } \\ \text { Itapura/Jupiá } & 1-35 \\ \text { Brotas } & 1-6\end{array}$

Itapura/Jupiá, Ilha

Solteira

Palmital

N.D.

Itapura/Jupiá

Itapura/Jupiá, Ilha

Solteira

São Paulo (citação)

N.D.

São Paulo (citação)

N.D.

São Carlos, Ribeira do Iguape

N.D.

Itapura/Jupiá

N.D.

São Paulo (citação)

N.D.

Profundidades mínimas e máximas registradas para a costa brasileira, quando disponíveis nas publicações (N.D.: Não disponível); Esponjas identificadas ao nível de gênero em trabalhos diferentes estão computadas como apenas um registro.

Minimum and maximum depths registered for the Brazilian coast, when available in the publications (N.D.: Not available); sponges identified at the genus level in distinct publications were listed as a single record. 
Dentre as identificações aparentemente incompletas listadas na Tabela 1, muitas certamente se provarão espécies novas após descrição e comparações detalhadas. Estas espécies ampliarão a lista de endêmicos provisórios do estado, porém talvez não de forma mais rápida que a expansão da lista de novos registros de espécies compartilhadas com Ecorregiões vizinhas. Os comentários biogeográficos que se seguem estão centrados nas 108 espécies totalmente identificadas - 12 de águas continentais e 96 marinhas.

Os grandes ecossistemas dulciaquícolas paulistas subdividem-se em três grandes bacias hidrográficas. A Bacia do Paraná que abarca mais de $80 \%$ da área do estado, e duas bacias menores, a Bacia do Atlântico Sudeste e a do Atlântico Sul, esta última apenas no extremo sul do estado. Corvomeyenia thumi, Dosilia pydanieli, Eunapius fragilis e Trochospongilla variabilis não tiveram suas localidades exatas de coleta registradas, e consequentemente não podem ser assinaladas a uma bacia específica. As demais espécies foram todas registradas na Bacia do Paraná, porém Corvospongilla seckti, Oncosclera navicella, Radiospongilla amazonensis e Uruguaia corallioides também foram registradas para a Bacia do Atlântico Sul. Desta forma, a Bacia do Atlântico Sudeste ainda permanece sem um registro sequer de porífero no Estado de São Paulo.

As esponjas marinhas também podem ser classificadas segundo seus padrões de distribuição. Treze espécies são endêmicas provisórias do Estado de São Paulo: Clathrina alcatraziensis, Dragmaxia anomala, Esperiopsis bathyalis, Halichondria migottea, H. sulfurea, H. tenebrica, Hamacantha microxifera, Mycale beatrizae, M. lilianae, M. purpurata, Rhabderemia besnardi, Sycon pentactinalis e Tedania birhaphidora. Além destas, outras seis espécies novas de Timea já foram registradas (Santos 2004), mas ainda não foram publicadas, o que elevaria este número para 20. Dezessete espécies são endêmicas provisórias da Ecorregião Sudeste do Brasil: Amorphinopsis atlantica, Aplysina caissara, Asteropus brasiliensis, Ciocalypta alba, Clathrina conifera, C. tetractina, Erylus soesti, Guitarra sepia, Halichondria cebimarensis, Halicometes minuta, Mycale arcuiris, Pachychalina alcaloidifera, Raspailia bouryesnaultae, Spongia catarinensis, Stelletta beae, Tedania brasiliensis e Tetilla radiata. Oito espécies adicionais são endêmicas provisórias do Brasil, ocorrendo além da Ecorregião Sudeste do Brasil: Clathrina aurea, Desmanthus meandroides, Geodia glariosa, Leucascus roseus, Mycale escarlatei, Petromica citrina, Polymastia janeirensis e Tethya maza. Trinta e sete espécies são amplamente distribuídas no Atlântico Tropical Ocidental, em alguns casos alcançando até a costa sudeste dos Estados Unidos e/ou Arquipélago das Bermudas: Amphimedon erina, A. viridis, Aplysina fulva, Artemisina aff. melana, Axinella corrugata, Callyspongia pallida, Cinachyrella alloclada, Clathria campecheae, Cliona dioryssa, Darwinella rosacea, Desmacella aff. pumilio, Dragmacidon reticulatum, Dysidea etheria, D. janiae, Euryspongia rosea, Geodia corticostylifera, G. papyracea, Haliclona melana, H. tubifera, Hymeniacidon heliophila, Lissodendoryx isodictyalis, Monanchora arbuscula, Mycale americana, M. angulosa, M. laxissima, M. magnirhaphidifera, M. microsigmatosa, Myxilla mucronata, Neopetrosia carbonaria, Oceanapia nodosa, Ptilocaulis marquezi, Scopalina hispida, S. ruetzleri, Suberites aurantiacus, Tedania ignis, Terpios fugax e Tethya diploderma. Finalmente, uma parte das espécies registradas para São Paulo tem distribuição em áreas mais distantes e aparentemente isoladas, o que levanta a possibilidade de se tratar de complexos de espécies. Esta categoria compreende 20 espécies: Aplysilla rosea, Characella pachastrelloides, Chelonaplysilla erecta, Chondrilla nucula, Chondrosia aff. reniformis, Clathrina primordialis, Cliona aff. celata, Desmacella annexa, Geodia gibberosa, Guancha blanca, Higginsia strigilata, Hymenancora tenuissima, Myxilla chilensis, Pachastrella monilifera, Paraleucilla magna, Raspailia phakellina, Rhabderemia uruguaiensis, Suberites caminatus, Timea authia e T. stellata. Este grupo incluiu também espécies com registros mais austrais, o que é comum dentre as espécies de plataforma e talude de São Paulo, que neste caso, não devem ter suas identificações duvidadas a priori. As espécies de notória afinidade austral (Patagônica, Magalhânica, Sub-Antártica e mesmo Antártica) são Hymenancora tenuissima, Myxilla chilensis, Raspailia phakellina, Rhabderemia uruguaiensis e Suberites caminatus. O grupo preponderante é o de espécies amplamente distribuídas no Atlântico Tropical Ocidental (37). Porém o somatório dos grupos provisoriamente endêmicos de São Paulo (14), da Ecorregião Sudeste (17) e do Brasil (8), totaliza 39 espécies, ultrapassando assim ao primeiro, e denotando o valor estratégico de preservação de áreas marinhas neste setor do litoral brasileiro.

\section{Principais Lacunas do Conhecimento}

Embora várias espécies ainda devam ser adequadamente descritas, o número de registros certamente está mais próximo ao estimado. No entanto, ainda existem lacunas a serem preenchidas. O litoral norte está relativamente bem representado, mas certamente novos registros podem ser feitos no litoral e em ilhotas e lajes submersas mais ao sul e nas águas continentais no interior do estado. A fauna existente em águas mais profundas apenas começou a ser investigada de maneira mais intensiva. Como ilustração, apenas as esponjas pertencentes ao gênero Asbestopluma coletadas recentemente na Bacia de Campos (RJ) apresentaram oito espécies novas (D. Lopes \& E. Hajdu, observação pessoal). É de se imaginar que a Bacia de Santos também tenha uma rica fauna associada a seus corais de profundidade. As poucas coletas efetuadas até o momento já colocam o Estado de São Paulo como o mais bem representado em termos de fauna de esponjas de águas profundas (Sumida et al. 2004, Hajdu \& Lopes 2007). Tendo em vista o futuro aproveitamento da região para a produção de petróleo na camada do pré-sal, seria de extrema importância um olhar mais atento para esta área.

No caso das esponjas de água doce, embora se tratando de um universo menor de espécies, certamente ainda há o que ser trabalhado. Esponjas de águas continentais necessitam de substratos consolidados para fixação, que nos habitats naturais são representados por rochas ou mesmo troncos. No entanto, podem também perfeitamente se utilizar de substratos artificiais, como represas e pilares de pontes, e estes são abundantes no estado. Em São Paulo, a maioria dos registros está concentrada ao oeste, próximo ao Rio Paraná, mas há ocorrência de espécies mesmo em áreas impactadas e mais próximas a centros urbanos, como Metania spinata, presente em um pequeno açude em meio a pastagens em Brotas (Lagoa Dourada) (Melão \& Rocha 1998, 1999; Pinheiro et al. 2003). Regiões bem preservadas podem guardar novas ocorrências. Por exemplo, apenas uma espécie, Radiospongilla amazonensis, já foi citada para as matas bastante preservadas da região de Ribeira do Iguape (Volkmer-Ribeiro 1999). Além disso, ainda há alguns registros que apontam a presença de espécies em outros estados ao norte e ao sul de São Paulo, e.g. Ephydatia facunda e Drulia brownii, já encontradas nas regiões Norte, Nordeste, Centro-Oeste e Sul (Pinheiro 2007). Desta forma, a intensificação de iniciativas voltadas especificamente para o levantamento da fauna de esponjas de águas continentais seriam bem vindas.

\section{Perspectivas Para os Próximos 10 Anos}

Nos últimos dez anos, houve um crescimento expressivo do conhecimento a respeito da fauna de esponjas do Estado de São Paulo. Um sintoma periférico, mas bastante ilustrativo deste aumento na base de conhecimento pode ser observado em teses e dissertações versando sobre ecologia de costões rochosos ou outros grupos de organismos. Nas mais antigas são frequentemente encontradas descrições tais como "associados a crostas de esponja"; nas mais recentes, estas já se encontram substituídas por "associados a Amphimedon viridis". 
Ao se fazer este levantamento, a importância de uma base taxonômica sólida fica patente quando se verifica o número de espécies utilizadas em trabalhos voltados à prospecção de produtos naturais. De fato, boa parte do conhecimento faunístico sobre esponjas gerado na última década pode ser atribuído a uma única parceria, estabelecida entre o grupo de Química Orgânica de Produtos Naturais da USP de São Carlos (RGS Berlinck) e o Laboratório de Taxonomia de Poríferos (E Hajdu). No entanto, tais iniciativas são dinâmicas e tendem a voltar seus interesses para outras áreas, e isso é preocupante para a pesquisa em Porifera em São Paulo. Outro benefício claro e comum também a outros grupos é o conhecimento da biota local. Tais informações são fundamentais na definição de políticas de desenvolvimento e no diagnóstico de impactos locais, como detecção de espécies invasoras ou degradação ambiental. Isto é bem ilustrado neste levantamento pelas espécies Higginsia strigilata e Ptilocaulis marquezi. Estas espécies foram coletadas respectivamente em 1964 e 1988 no Canal de São Sebastião, mas desde então não foram mais registradas, a despeito das coletas intensivas na região (Carvalho 2003).

Como colocado no levantamento anterior feito em 1999 (Hajdu et al. 1999), o Estado de São Paulo ainda não conta com um único pesquisador especialista dedicado à taxonomia de Porifera. Seria, portanto, altamente recomendável o incentivo à formação e fixação de pessoal que pudesse garantir a continuidade das pesquisas no grupo.

\section{Agradecimentos}

Os autores agradecem à FAPESP, FAPERJ, CNPq, CAPES e PETROBRAS por bolsas e/ou financiamentos. Ao Prof. Marcos

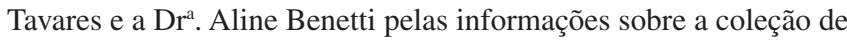
Porifera no Museu de Zoologia (USP). Ao Prof. Ulisses Pinheiro (Departamento de Zoologia, UFPE) por dados sobre as esponjas continentais.

\section{Referências Bibliográficas}

ABDO, D.A. 2007. Endofauna differences between two temperate marine sponges (Demospongiae; Haplosclerida; Chalinidae) from southwest Australia. Mar. Biol. 152:845-854. http://dx.doi.org/10.1007/s00227007-0736-7

AMARAL, A.C.Z., LANA, P.C., FERNANDES, F.C. \& COIMBRA, J.C. 2004 Caracterização do ambiente e da macrofauna bentônica. In Biodiversidade bentônica da região sudeste-sul do Brasil - Plataforma externa e talude superior (A.C.Z. Amaral \& C.L.D.B. Rossi-Wongtschowski, org.). Série documentos Revizee: Score Sul. Instituto Oceanográfico - USP, São Paulo, p.11-46.

BATISTA, T.C.A., VOLKMER-RIBEIRO, C. \& MELÃO, M.G.G. 2007. Espongofauna da área de proteção ambiental meandros do rio Araguaia (GO, MT, TO), Brasil, com descrição de Heteromeyenia cristalina sp. nov. (Porifera, Demospongiae). Rev. Bras. Zool. 24:608-630. http://dx.doi. org/10.1590/S0101-81752007000300013

BERLINCK, R.G.S., HAJDU, E., ROCHA, R.M., OLIVEIRA, J.H., HERNANDEZ, I.L., SELEGHIM, M.H.R., GRANATO, A.C., ALMEIDA, E.V., NUNEZ, C.V., MURICY, G., PEIXINHO, S., PESSOA, C., MORAES, M.O., CAVALCANTI, B.C., NASCIMENTO, G.G.F., THIEMANN, O.H., SILVA, M., SOUZA, A.O., SILVA, C.L. \& MINARINI, P.R. 2004. Challenges and rewards of research in marine natural products chemistry in Brazil. J. Nat. Prod. 67(3):510-522. PMid:15043447. http://dx.doi.org/10.1021/np0304316

BERLINCK, R.G.S., OGAWA, C.A., ALMEIDA, A.M.P., SANCHEZ, M.A., MALPEZZI, E.L.A., COSTA, L.V., HAJDU, E. \& FREITAS, J.C. 1996. Chemical and pharmacological characterization of halitoxin from Amphimedon viridis (Porifera) from the southeastern Brazilian coast. Comp. Biochem. Physiol. C 115(2):155-163. PMid:9568363.

BLUNT, J.W., COPP, B.R., HU, W.P., MUNRO, M.H.G., NORTHCOTE, P.T. \& PRINSEP, M.R. 2009. Marine natural products. Nat. Prod. Rep. 26:170-244. PMid:19177222. http://dx.doi.org/10.1039/b805113p
BORCHIELLINI, C., MANUEL, M., ALIVON, E., BOURY-ESNAULT, N., VACELET, J. \& LE PARCO, Y. 2001. Sponge paraphyly and the origin of Metazoa. J. Evol. Biol. 14(1):171-179. http://dx.doi.org/10.1046/j.14209101.2001.00244.x

BOROJEVIC, R. 1971. Eponges calcaires de côte sud-est du Brésil, épibiontes sur Laminaria brasiliensis et Sargassum cymosum. Rev. Bras. Biol. 31:525-530.

BOURY-ESNAULT, N. 1973. Spongiaires. Ann. Inst. Oceanographique 49(S10):263-295.

BOURY-ESNAULT, N. 2006. Systematics and evolution of Demospongiae. Can. J. Zool. 84(2):205-224. http://dx.doi.org/10.1139/z06-003

BOURY-ESNAULT, N., HAJDU, E., KLAUTAU, M., CUSTÓDIO, M.R. \& BOROJEVIC, R. 1994. The value of cytological criteria in distinguishing sponges at species level: the example of the genus Polymastia. Can. J. Zool. 72(5):795-804. http://dx.doi.org/10.1139/z94-108

BUGNI, T. \& IRELAND, C. 2004. Marine-derived fungi: a chemically and biologically diverse group of microorganisms. Nat. Prod. Rep. 21:143-163. PMid:15039840. http://dx.doi.org/10.1039/b301926h

CARBALLO, J.L. \& HAJDU, E. 1998. Micromorphology in Mycale taxonomy (Mycalidae, Poecilosclerida, Demospongiae), with the description of two new micracanthoxea-bearing species. Contrib. Zool. 67(3):187-195

CARBALLO, J.L. \& HAJDU, E. 2001. Mycale (Aegogropila) kolletae sp. n. from the SE Atlantic, with comments on the species of Mycale Gray with raphidotoxas (Mycalidae, Demospongiae, Porifera). Rev. Bras. Zool. 18(S1):205-217.

CARVALHO, J.P. 1942. Ocorrência de Ephydatia crateriformis (Potts) na América do Sul. Bol. Fac. Fil. Ci. Letras, Univ. São Paulo 6:267-269.

CARVALHO, M.S. 2003. Taxonomia de esponjas da ordem Halichondrida (Demospongiae, Porifera) do litoral norte do Estado de São Paulo. Dissertação de mestrado, Universidade Federal do Rio de Janeiro.

CARVALHO, M.S. 2008. Taxonomia, filogenia e biogeografia de esponjas marinhas do Chile: ordens Astrophorida e Halichondrida. Tese de Doutorado, Universidade Federal do Rio de Janeiro.

CARVALHO, M.S. \& HAJDU, E. 2001. Comments on brazilian Halichondria Fleming (Halichondriidae, Halichondrida, Demospongiae), with the description of four new species from the São Sebastião Channel and its environs (Tropical Southwestern Atlantic). Rev. Bras. Zool. 18(S1):161-180.

CARVALHO, M.S. \& HAJDU, E. 2004. Dragmaxia anomala sp.n. (Demospongiae: Halichondrida) from the southwestern Atlantic (Brazil). Zootaxa 400:1-6.

CARVALHO, M.S., CARRARO, J.L., LERNER, C.B. \& HAJDU, E. 2003. First record of Ciocalypta (Demospongiae: Halichondrida) from Brazil, southwestern Atlantic, with the description of a new species. Zootaxa 302:1-18. http://dx.doi.org/10.1590/S0101-81752001000500013

CARVALHO, M.S., HAJDU, E., MOTHES, B. \& VAN SOEST, R.W.M. 2004. Amorphinopsis (Halichondrida: Demospongiae) from the Atlantic Ocean, with the description of a new species. J. Mar. Biol. Assoc. UK 84(5):925930. http://dx.doi.org/10.1017/S0025315404010203h

CHEHADE, C.C., DIAS, R.L., BERLINCK, R.G.S., FERREIRA, A.G., COSTA, L.V., RANGEL, M., MALPEZZI, E.L.A., FREITAS, J.C. \& HAJDU, E. 1997. 1,3-Dimethylisoguanine, a new purine from the marine sponge Amphimedon viridis. J. Nat. Prod. 60(7):729-731. PMid:9249981. http://dx.doi.org/10.1021/np970021f

ÇINAR, M.E., KATAGAN, T., ERGEN, Z. \& SEZGIN, M. 2002. Zoobenthos-inhabiting Sarcotragus muscarum (Porifera: Demospongiae) from the Aegean Sea. Hydrobiologia 482:107-117. http://dx.doi. org/10.1023/A:1021260314414

CORBI, J.J., ROQUE, F.O., TRIVINHO-STRIXINO, S. \& ALVES, R.G. 2005 . Records of oligochaetes in freshwater sponges, on bryozoans, and on colonial hydrozoans from Brazil. Braz. J. Biol. 65(1):187-188. http:// dx.doi.org/10.1590/S1519-69842005000100022

CUSTÓDIO, M.R., HAJDU, E. \& MURICY, G. 2002. In vivo study of microsclere formation in sponges of the genus Mycale (Demospongiae, Poecilosclerida). Zoomorphology 121(4):203-211. http://dx.doi. org/10.1007/s00435-002-0057-9

CUSTÓDIO, M.R., HAJDU, E. \& MURICY, G. 2004. Cellular dynamics of in vitro allogeneic reactions of Hymeniacidon heliophila (Demospongiae, Halichondrida). Mar. Biol. 144:999-1010. http://dx.doi.org/10.1007/ s00227-003-1265-7 
DE GOEIJ, J.M., VAN DEN BERG, H., VAN OOSTVEEN, M.M., EPPING, E.H.G., \& VAN DUYL, F.C. 2008. Major bulk dissolved organic carbon (DOC) removal by encrusting coral reef cavity sponges. Mar. Ecol. Progr. Ser. 357:139-151. http://dx.doi.org/10.3354/meps07403

DE GOEIJ, J.M., DE KLUIJVER, A., VAN DUYL, F.C., VACELET, J., WIJFFELS, R.H., DE GOEIJ, A.F.P.M., CLEUTJENS, J.P.M., SCHUTTE, B. 2009. Cell kinetics of the marine sponge Halisarca caerulea reveal rapid cell turnover and shedding. J. Exp. Biol. 212:3892-3900. http://dx.doi. org/10.1242/jeb.034561

DE LAUBENFELS, M.W. 1956. Preliminary discussion of the sponges of Brazil. Bol. lnst. Oceanogr. São Paulo (1):1-4.

DUARTE, L.F.L. 1980. A endofauna da esponja Zygomycale parishi (Bowerbank) composição, dominância, diversidade e natureza da associação. Dissertação de Mestrado, Universidade Estadual de Campinas.

DUARTE, L.F.L. \& MORGADO, E.H. 1983. Crustáceos parasitos de invertebrados associados à esponja Zygomycale parishi (Bowerbank) e ao briozoário Schizoporella unicornis (Johnston, 1847). Iheringia 62:3-11.

DUARTE, L.F.L. \& NALESSO, R.C. 1996. The sponge Zygomycale parishi (Bowerbank) and its endobiotic fauna. Estuar. Coast. Shelf Sci. 42(2):139151. http://dx.doi.org/10.1006/ecss.1996.0011

ENTICKNAP, J., KELLY, M., PERAUD, O. \& HILL, R. 2006. Characterization of a culturable alphaproteobacterial symbiont common to many marine sponges and evidence for vertical transmission via sponge larvae. Appl. Environ. Microbiol. 72:3724-3732. PMid:16672523. PMCid:1472332. http://dx.doi.org/10.1128/AEM.72.5.3724-3732.2006

FROST, T.M., DENAGY, G.S. \& GILBERT, J.J. 1982. Population-dynamics and standing biomass of the fresh-water sponge Spongilla lacustris. Ecology 63(5):1203-1210. http://dx.doi.org/10.2307/1938844

FUSARI, L.M., ROQUE, F.O. \& HAMADA, N. 2008. Sponge-dwelling chironomids in the upper Paraná river (Brazil): little known but potentially threatened species. Neotropical Entomol. 37(5):522-527. PMid:19061036. http://dx.doi.org/10.1590/S1519-566X2008000500004

GORNI, G.R. \& ALVES, R.G. 2008. Naididae species (Annelida: Oligochaeta) associated with the sponge Metania spinata (Carter, 1881) (Porifera: Metaniidae) from a southeastern Brazilian reservoir. Acta Limnol. Bras. 20(3):261-263.

GRANATO, A.C., BERLINCK, R.G.S., MAGALHÃES, A., SCHEFER, A.B., FERREIRA, A.G., SANCTIS, B,. FREITAS, J.C., HAJDU, E. \& MIGOTTO, A.E. 2000. Produtos naturais das esponjas marinhas Aaptos sp., Hymeniacidon aff. heliophila, e do nudibrânquio Doris aff. Verrucosa. Quim. Nov. 23(5):594-599.

GRAY, C.A., LIRA, S.P., SILVA, M., PIMENTA, E.F., THIEMANN, O.H., OLIVA, G., HAJDU, E., ANDERSEN, R.J. \& BERLINCK, R.G.S. 2006. Sulfated meroterpenoids from the Brazilian sponge Callyspongia sp. are Inhibitors of the antileishmaniasis target adenosine phosphoribosyl transferase. J. Org. Chem. 71(23):1062. PMid:17080994. http://dx.doi. org/10.1021/jo060295k

HAJDU, E. \& BOURY-ESNAULT, N. 1991. Marine Porifera of Cabo Frio (Rio de Janeiro, Brazil): the family Mycalidae Lundbeck 1905 with the description of a new species. Rev. Bras. Biol. 51(3):503-513.

HAJDU, E. \& CARVALHO, M.S. 2003. A new species of Stelletta (Porifera, Demospongiae) from the southwestern Atlantic. Arq. Mus. Nac. 61(1):3-12.

HAJDU, E. \& DESQUEYROUX-FAÚNDEZ, R. 1994. A synopsis of South American Mycale (Mycale) (Poecilosclerida, Demospongiae), with description of three new species and a cladistic analysis of Mycalidae. Rev. Suisse Zool. 101(3):563-600.

HAJDU, E. \& LOPES, D.A. 2007. Checklist of Brazilian deep-sea sponges. In Porifera research: biodiversity, innovation and sustainability (M.R. Custódio, G. Lôbo-Hajdu, E. Hajdu \& G. Muricy, eds.). Série Livros 28. Museu Nacional, Rio de Janeiro, p.353-359.

HAJDU, E., BERLINCK, R.G.S. \& FREITAS, J.C. 1999. Porifera. In Biodiversidade do Estado de São Paulo: síntese do conhecimento ao final do século XX. Invertebrados Marinhos (A. Migotto \& C.G. Tiago, eds.). FAPESP, São Paulo, v.3, p.20-30.

HAJDU, E., MURICY G., CUSTÓDIO, M., RUSSO, C. \& PEIXINHO, S. 1992. Geodia corticorticostylifera (Demospongiae, Porifera). New astrophorid from the brazilian coast (Southwestern Atlantic). Bull. Mar. Sc. 51(2):204-217.
HAJDU, E., SANTOS, C.P., LOPES, D.A., OLIVEIRA, M.V., MOREIRA, M.C.F., CARVALHO, M.S. \& KLAUTAU, M. 2004. Filo Porifera. Região Sul. In Biodiversidade bentônica da região sudeste-sul do Brasil - Plataforma Externa e Talude Superior (A.C.Z. Amaral, \& C.L.D.B. Rossi-Wongtschowski, eds.). Série Documentos Revizee - Score Sul. Ulhôa Cintra Ed., São Paulo, p.57-63.

HAJDU, E., SANTOS, C.P., LOPES, D.A., OLIVEIRA, M.V., MOREIRA, M.C.F., CARVALHO, M.S. \& KLAUTAU, M. 2004. Filo Porifera. In Biodiversidade bentônica da região sudeste-sul do Brasil - Plataforma Externa e Talude Superior (A.C.Z. Amaral, \& C.L.D.B. RossiWongtschowski, eds.). Série Documentos Revizee - Score Sul. Ulhôa Cintra Ed., São Paulo, p.49-56.

HENKEL, T.P. \& PAWLIK, J.R. 2005. Habitat use by sponge dwelling brittle stars. Mar. Biol. 146:301-13. http://dx.doi.org/10.1007/s00227004-1448-x

HOOPER, J.N.A. \& VAN SOEST, R.W.M. 2002. Systema Porifera: a guide to the classification of sponges. Kluwer Academic/Plenum Publishers, New York.

KLAUTAU, M., MONTEIRO, L. \& BOROJEVIC, R. 2004. First occurrence of the genus Paraleucilla (Calcarea, Porifera)in the Atlantic Ocean: $P$. magna sp.nov. Zootaxa 710:1-8.

KLAUTAU, M., RUSSO, C.A.M., LAZOSKI, C., BOURY-ESNAULT, N., THORPE, J.P. \& SOLÉ-CAVA, M. 1999. Does cosmopolitanism result from overconservative systematics? A case study using the marine sponge Chondrilla nucula. Evolution 53(5):1414-1422. http://dx.doi. org $/ 10.2307 / 2640888$

KNOPPERS, B.A., SOUZA, W.F.L., EKAU, W., FIGUEIREDO, A.G., SOARES-GOMES, A. 2009. A Interface Terra- Mar do Brasil. In Biologia Marinha (R.C.C. Pereira \& A. Soares-Gomes, orgs.). 2 ed. Interciência, Rio de Janeiro, p.529-553.

LAMARÃO, F.R.M. 2004. Caracterização molecular de esponjas do gênero Aplysina Nardo, 1834 da costa brasileira (Aplysinidae, Verongida, Demospongiae). Dissertação de mestrado, Universidade Estadual do Rio de Janeiro.

LANNA, E. 2008. Biologia reprodutiva de Paraleucilla magna (Porifera, Calcarea, Calcaronea) e sua relação com os fatores ambientais no Rio de Janeiro. Dissertação de Mestrado, Universidade Federal do Rio de Janeiro.

LANNA, E., ROSSI, A.L., CAVALCANTI, F.F., HAJDU, E. \& KLAUTAU, M. 2007. Calcareous sponges from São Paulo State, Brazil (Porifera: Calcarea: Calcinea) with the description of two new species. J. Mar. Biol. Assoc. UK 87(6):1553-1561. http://dx.doi.org/10.1017/ S0025315407056871

LANNA, E., CAVALCANTI, F.F., CARDOSO, L., MURICY, G. \& KLAUTAU, M. 2009. Taxonomy of calcareous sponges (Porifera, Calcarea) from Potiguar Basin, NE Brazil. Zootaxa 1973:1-27.

LAVRADO, H.P. 2006. Caracterização do ambiente e da comunidade bentônica. In Biodiversidade bentônica da região central da Zona Econômica Exclusiva Brasileira (H.P. Lavrado \& B.L. Ignácio, eds.). Série Livros 18. Museu Nacional, Rio de Janeiro, p.19-64.

LERNER, C.B. 2001. Inventariamento da fauna de poríferos da costa do Estado de Santa Catarina, Brasil. Tese de Doutorado, Universidade de São Paulo.

LERNER, C.B. \& HAJDU, E. 2002. Two new Mycale (Naviculina) Gray (Mycalidae, Poecilosclerida, Demospongiae) from the Paulista Biogeographic Province (Southwestern Atlantic). Rev. Bras. Zool. 19(1):109-122. http://dx.doi.org/10.1590/S0101-81752002000100009

LERNER, C.B., HAJDU, E., CUSTÓDIO, M.R. \& VAN SOEST, R.W.M. 2003. Guitarra sepia n.sp. from the southwestern Atlantic (Demospongiae, Poecilosclerida, Guitarridae). First record of a Guitarra without placochelae. Boll. Mus. Ist. biol. Univ. Genova 68(7):405-411.

LERNER, C.B., MOTHES, B. \& CARRARO, J.L. 2005. Novos registros e ampliação de limites meridionais de distribuição de poríferos (Porifera, Demospongiae) no Atlântico sudoeste. Rev. Bras. Zool. 22(3):596-612. http://dx.doi.org/10.1590/S0101-81752005000300012

LIRA, S.P. 2007. Metabólitos secundários biologicamente ativos isolados de esponjas marinhas e do fungo Beauveria felina de origem marinha. Tese de Doutorado, Universidade de São Paulo.

LIRA, T.O., BERLINCK, R.G.S., NASCIMENTO, G.G.F. \& HAJDU, E. 2006. Further dibromotyrosine-derived metabolites from the marine sponge Aplysina caissara. J. Braz. Chem. Soc. 17(7):1233-1240. http:// dx.doi.org/10.1590/S0103-50532006000700007 
LIRA, S.P., SELEGHIM, M.H.R., WILLIAMS, D.E., MARION, F., HAMILL, P., JEAN, F., ANDERSEN, R.J., HAJDU, E. \& BERLINCK, R.G.S. 2007. A SARS-coronovirus 3CL protease inhibitor isolated from the marine sponge Axinella cf. corrugata: structure elucidation and synthesis. J. Braz. Chem. Soc. 18(2):440-443. http://dx.doi.org/10.1590/S010350532007000200030

LÔBO-HAJDU, G., MANSURE, J.J., SALGADO, A., HAJDU, E., MURICY, G. \& ALBANO, R.M. 1999. Random amplified polymorphic DNA (RAPD) analysis can reveal intraspecific evolutionary patterns in Porifera. Mem. Queensland Mus. 44:317-328.

LÔBO-HAJDU, G., GUIMARÃES, A.C.R, SALGADO, A., LAMARÃO, F.R.M., VIEIRALVES, T., MANSURE, J.J. \& ALBANO, R.M. 2003. Intragenomic, intra- and interspecific variation in the RDNA ITS of Porifera revealed by PCR-single-strand conformation polymorphis (PCRSSC.P.). Boll. Mus. Ist. biol. Univ. Genova 68:413-423.

LOPES, D.A. \& HAJDU, E. 2004. Two new Mycalina from the southeastern Brazilian shelf and slope collected by programme REVIZEE (Poecilosclerida: Demospongiae). J. Mar. Biol. Assoc. UK 84:25-28. http://dx.doi.org/10.1017/S0025315404008860h

MAJER, A.P. 2008. Ecologia de ofiuróides associados a microhabitats biológicos. Tese de Doutorado, Universidade Estadual de Campinas.

MELÃO, M.G.G. 1999. Biomass and productivity of the freshwater sponge Metania spinata (Carter, 1881) (Demospongiae: Metaniidae) in a Brazilian Reservoir. Hydrobiologia 390:1-10.

MELÃO, M.G.G. \& ROCHA, O. 1996a. Consumo e taxas de filtração de Metania spinata (Porifera, Metaniidae). In Anais do VII Seminário Regional de Ecologia. São Carlos, SP, Brasil, 7:87-93.

MELÃO, M.G.G. \& ROCHA, O. 1996b. Germinação de gêmulas de Metania spinata (Porifera, Metaniidae). In Anais do VII Seminário Regional de Ecologia. São Carlos, SP, Brasil, 7:81-85.

MELÃO, M.G.G. \& ROCHA, O. 1996c. Macrofauna associada à Metania spinata (Carter, 1881) (Porifera, Metaniidae). Acta Limnol. Bras. 8:59-64.

MELÃO, M.G.G. \& ROCHA, O. 1996d. Ocorrência, mapeamento e biomassa instantânea de Metania spinata (Carter, 1881), Porifera, Metaniidae, na Lagoa Dourada (Brotas, SP). Acta Limnol. Bras. 8:65-74.

MELÃO, M.G.G. \& ROCHA, O. 1997. Associação simbiótica de Metania spinata (Porifera, Metaniidae) com uma Chlorophyceae. Braz. J. Ecol. $1: 1-9$.

MELÃO, M.G.G. \& ROCHA, O. 1998. Growth rates and energy budget of Metania spinata (Cartes 1881) (Porifera, Metaniidae) in Lagoa Dourada, Brazil. In Proceedings of the International Association of Theoretical and Applied Limnology, 26:2098-2102.

MELÃO, M.D.G. \& ROCHA, O. 1999. Biomass and productivity of the freshwater sponge Metania spinata (Carter, 1881) (Demospongiae: Metaniidae) in a Brazilian reservoir. Hydrobiologia 390(1-3):1-10.

MENEZES, C.B., BONUGLI-SANTOS, R.C., MIQUELETTO, P.B., PASSARINI, M.R., SILVA, C.H., JUSTO, M.R., LEAL, R.R., FANTINATTI-GARBOGGINI, F., OLIVEIRA, V.M., BERLINCK, R.G.S. \& SETTE, L.D. 2009. Microbial diversity associated with algae, ascidians and sponges from the north coast of Sao Paulo state, Brazil. Microbiol. Res. 2009/11/03.

MILANETTO, M.C. 2008. Investigação da origem metabólica de derivados da esculetina ativos contra o vírus da SARS. Dissertação de Mestrado, Universidade de São Paulo.

MOTHES, B. 1980. Esponjas de São Sebastião, litoral de São Paulo, Brasil (Porifera, Demospongiae). Iheringia 56:75-86.

MOTHES, B. 1985. Sponges collected by the Oxford diving expedition, to the Cabo Frio upwelling area (Rio de Janeiro, Brasil). Stud. Neotrop. Fauna Environ. 20(4):227-237. http://dx.doi.org/10.1080/01650528509360694

MOTHES, B. \& LERNER, C.B. 2001. A new species of Erylus Gray, 1867 (Porifera, Geodiidae) from the southeastern coast of Brazil. Beaufortia 51(4):83-89.

MOTHES, B., HAJDU, E. \& VAN SOEST, R.W.M. 2000. Tedania brasiliensis new species (Demospongiae, Poecilosclerida, Tedaniidae) from Brazil, with some remarks about the genus Tedania in the tropical southwestern Atlantic. Bull. Mar. Sci. 66(1):1-11.

MOTHES, B., LERNER, C.B. \& SILVA, C.M.M. 2003. Guia ilustrado: esponjas marinhas. Costa sul-brasileira. Coleção Manuais de Campo USEB. Pelotas.
MÜLLER, W.E.G. 1998. Molecular phylogeny of Eumetazoa: experimental evidence for monophyly of animals based on genes in sponges (Porifera). Prog. Mol. Subcell. Biol. 19:98-132.

MURICY, G., ESTEVES, E.L., MORAES, F., SANTOS, J.P., SILVA, S.M., KLAUTAU, M. \& LANNA, E. 2008. Biodiversidade Marinha da Bacia Potiguar: Porifera. Série Livros 29. Museu Nacional, Rio de Janeiro.

MURICY, G. \& HAJDU, E. 2006. Porifera Brasilis: Guia de identificação das esponjas marinhas mais comuns do sudeste do Brasil. Série Livros 17. Museu Nacional, Rio de Janeiro.

MURICY, G., HAJDU, E., MINERVINO, J.V., MADEIRA, A.V. \& PEIXINHO, S. 2001. Systematic revision of the genus Petromica Topsent (Demospongiae: Halichondrida), with a new species from the southwestern Atlantic. Hydrobiologia 443(1-3):103-128. http://dx.doi. org/10.1023/A:1017504422239

MURICY, G., HAJDU, E., OLIVEIRA, M.V., HEIM, A.S., COSTA, R.N., LOPES, D.A., MELÃO, M., RODRIGUEZ, P.R.D., SILVANO, R., MONTEIRO, L. \& SANTOS, C.P. 2007. Filo Porifera. In Atlas de Invertebrados Marinhos da região Central da Zona Econômica Exclusiva brasileira. Parte 1(H.P. Lavrado \& M.S. Viana). Série Livros 25. Museu Nacional. Rio de Janeiro, p.25-57.

MURICY, G. \& RIBEIRO, S.M. 1999. Shallow-water Haplosclerida (Porifera, Demospongiae) from Rio de Janeiro state, Brazil (southwestern Atlantic). Beaufortia 49(9):83-108.

MURICY, G. \& SILVA, O.C. 1999. Esponjas marinhas do Estado do Rio de Janeiro: um recurso renovável inexplorado. In Ecologia dos ambientes costeiros do Estado do Rio de Janeiro (S.G.H. Silva \& H.P. Lavrado, ed.). Série Oecologia Brasiliensis. PPGE-UFRJ, v.7, p.155-178.

NUNEZ, C.V., ALMEIDA, E.V., GRANATO, A.C., MARQUES, S.O., SANTOS, K.O., PEREIRA, F.R., MACEDO, M.L., FERREIRA, A.G., HAJDU, E., PINHEIRO, U.S., MURICY, G., PEIXINHO, S., FREEMAN, C.J., GLEASON, D.F. \& BERLINCK, R.G.S. 2008. Chemical variability within the marine sponge Aplysina fulva. Biochem. Syst. Ecol. 36(4):283-296. http://dx.doi.org/10.1016/j.bse.2007.09.008

OLIVEIRA, D.A. 2004. Distribuição espacial e temporal dos anfipodes gamarideos assocados a diferentes substratos secundarios de costão rochoso de praias do litoral norte do Estado de São Paulo. Dissertação de Mestrado, Universidade Estadual de Campinas.

OLIVEIRA, M.V. \& HAJDU, E. 2005. Taxonomy of Rhabderemia Topsent, 1890 collected from the south-eastern Brazilian continental shelf and slope by Programme REVIZEE (Rhabderemiidae, Poecilosclerida, Demospongiae), with the description of two new species. Zootaxa 844:1-12.

PEREIRA, F.R. 2006. Avaliação da variação do metabolismo secundário da esponja marinha Aplysina fulva em função de sua distribuição geográfica. Dissertação de Mestrado, Universidade de São Paulo.

PINHEIRO, U.S. 2007. Contribuições à taxonomia e biogeografia das esponjas de águas continentais brasileiras. Tese de Doutorado, Universidade Federal do Rio de Janeiro.

PINHEIRO, U.S. \& HAJDU, E. 2001. Shallow-water Aplysina Nardo (Aplysinidae, Verongida, Demospongiae) from the São Sebastião Channel and its environs (Tropical southwestern Atlantic), with the description of a new species and a literature review of other brazilian records of the genus. Rev. Bras. Zool. 18(S1):143-160. http://dx.doi.org/10.1590/ S0101-81752001000500012

PINHEIRO, U.S., BERLINCK, R.G.S. \& HAJDU, E. 2005. Shallow-water Niphatidae (Haplosclerina, Haplosclerida, Demospongiae) from the São Sebastião Channel and its environs (tropical southwestern Atlantic), with the description of a new species. Contrib. Zool. 74(3-4):271-278.

PINHEIRO, U.S., HAJDU, E. \& CABALLERO, M.E. 2003. Three new records of freshwater sponges (Porifera, Demospongiae) for Sao Paulo State. Bol. Mus. Nac. Zool. 498:1-14.

PINHEIRO, U.S., HAJDU, E. \& CUSTÓDIO, M.R. 2004. Cell types as taxonomic characters in Aplysina (Aplysinidae, Verongida). Boll. Mus. Ist. Biol. Univ. Genova 68:527-533.

PINHEIRO, U.S., HAJDU, E. \& CUSTÓDIO, M.R. 2007. Aplysina Nardo (Porifera, Verongida, Aplysinidae) from the Brazilian coast with description of eight new species. Zootaxa 1609:1-51.

PRADO, M.P. 2007. Compostos bioativos extraídos de esponjas: Citotoxicidade e mecanismo de ação sobre o citoesqueleto de células de tumor de mama em cultura. Tese de Doutorado, Universidade de São Paulo. 
RANGEL, M., SANCTIS, B., FREITAS, J.C., POLATTO, J.M., GRANATO, A.C., BERLINCK, R.G.S. \& HAJDU, E. 2001. Cytotoxic and neurotoxic activities in extracts of marine sponges (Porifera) from southeastern Brazilian coast. J. Exp. Mar. Biol. Ecol. 262(1):31-40. http://dx.doi. org/10.1016/S0022-0981(01)00276-3

RANGEL, M., KONNO, K., BRUNALDI, K., PROCOPIO, J. \& FREITAS, J.C. 2005. Neurotoxic activity induced by a haemolytic substance in the extract of the marine sponge Geodia corticostylifera. Comp. Biochem. Physiol. C 141(2):207-215.

RANGEL, M., PRADO, M.P., KONNO, K., NAOKI, H., FREITAS, J.C. \& MACHADO-SANTELLI, G.M. 2006. Cytoskeleton alterations induced by Geodia corticostylifera depsipeptides in breast cancer cells. Peptides 27(9):2047-2057. http://dx.doi.org/10.1016/j.peptides.2006.04.021

RIBEIRO, S.M., OMENA, E.P. \& MURICY, G. 2003. Macrofauna associated to Mycale microsigmatosa (Porifera, Demospongiae) in Rio de Janeiro State, SE Brazil. Estuar. Coast. Shelf Sci. 57:951-959. http://dx.doi. org/10.1016/S0272-7714(02)00425-0

ROCHA, L.A., ROSA, I.L., FEITOZA, B.M. 2000. Sponge-dwelling fishes of northeastern Brazil. Env. Biol. Fish 59:453-458. http://dx.doi. org/10.1023/A:1026584708092

ROCHA, R.M. 1993. Comunidade incrustante em substrato duro não estabilizado na zona entremarés (São Sebastião, SP). Tese de Doutorado, Universidade Estadual de Campinas.

ROCHA, R.M. 1995. Abundance and distribuition of sessile invertebrates under intertidal boulders (São Paulo, Brazil). Bol. Inst. Ocean. São Paulo 43(1):71-88

ROQUE, F.O. \& TRIVINHO-STRIXINO, S. 2005. Xenochironomus ceciliae (Diptera: Chironomidae), a new chironomid species inhabiting freshwater sponges in Brazil. Hydrobiologia 534(1-3):231-238. http://dx.doi. org/10.1007/s10750-004-1636-1

ROQUE, F.O., TRIVINHO-STRIXINO, S., COUCEIRO, S.R.M., HAMADA, N., VOLKMER-RIBEIRO, C. \& MESSIAS, M.C. 2004. Species of Oukuriella Epler (Diptera, Chironomidae) inside freshwater sponges in Brazil. Rev. Bras. Entomol. 48(2):291-292.

ROSSI, A.L., FARINA, M., BOROJEVIC, R. \& KLAUTAU, M. 2006. Occurrence of five-rayed spicules in a calcareous sponge: Sycon pentactinalis sp.nov. (Porifera: Calcarea). Cah. Biol. Mar. 47(3):261-270.

SAEKI, B.M., GRANATO, A.C., BERLINCK, R.G.S., MAGALHAES, A., SCHEFER, A.B., FERREIRA, A.G. PINHEIRO, U.S. \& HAJDU, E. 2002. Two unprecedented dibromotyrosine-derived alkaloids from the Brazilian endemic marine sponge Aplysina caissara. J. Nat. Prod. 65(5):796-799. http://dx.doi.org/10.1021/np0105735

SANTOS, C.P. 2004. Revisão taxonômica de Timea Gray. 1867 (Timeidae, Hadromerida, Porifera) da costa brasileira. Dissertação de Mestrado, Universidade Federal do Rio de Janeiro.

SANTOS, C.P. \& HAJDU, E. 2003. Redescription of Tetilla radiata Selenka from the Southwestern Atlantic (Porifera, Spirophorida, Tetillidae) and designation of its neotype. Rev. Bras. Zool. 20(4):637-642. http://dx.doi. org/10.1590/S0101-81752003000400013

SANTOS, C.P., HAJDU, E. \& MURICY, G. 2003. An identification system for common Demospongiae of the Sao Sebastiao Channel area, SW Atlantic, developed with the Linnaeus II software. Boll. Mus. Ist. Biol. Univ. Genova 68:587-591

SELEGHIM, M.H.R., LIRA, S.P., KOSSUGA, M.H., BATISTA, T., BERLINCK, R.G.S., HAJDU, E., MURICY, G., ROCHA, R.M., NASCIMENTO, G.G.F., SILVA, M., PIMENTA, E.F., THIEMANN, O.H., OLIVA, G., CAVALCANTI, B.C., PESSOA, C., MORAES, M.O., GALETTI, F.C.S., SILVA, C.L., SOUZA, A.O. \& PEIXINHO, S. 2007. Antibiotic, cytotoxic and enzyme inhibitory activity of crude extracts from Brazilian marine invertebrates. Rev. Bras. Farmacogn. 17(3):287-318. http://dx.doi.org/10.1590/S0102-695X2007000300002

SHARP, K.H., EAM, B., FAULKNER, D.J. \& HAYGOOD, M.G. 2007. Vertical transmission of diverse microbes in the tropical sponge Corticium sp. Appl. Environ. Microbiol. 73(2):622-629. http://dx.doi.org/10.1128/ AEM.01493-06

SHIMABUKURO, V. 2007. As associações epizóicas de Hydrozoa (Cnidaria): I) Estudo faunístico de hidrozoários epizóicos e seus organismos associados, II) Dinâmica de comunidades bentônicas em substratos artificiais em São Sebastião, S.P. Dissertação de Mestrado, Universidade de São Paulo.
SHIRAISHI, R.S. 1978. CG-EM dos esteroides da esponja Tedania ignis e espectrometria de massa dos derivados do colesterol. Dissertação de Mestrado, Universidade Estadual de Campinas.

SILVA, C.M.M. 2002. Revisão das espécies de Geodia Lamarck, 1815 (Porifera, Astrophorida, Geodiidae) do Atlântico Ocidental e Pacífico Oriental. Tese de Doutorado, Universidade de São Paulo.

SILVA, C.M.M. \& VOLKMER-RIBEIRO, C. 1998. Ethiopian species of the genus Metania (Porifera, Metaniidae): I. Redescription of M. pottsi, comb.n. Iheringia 85:157-168.

SILVA, C.M.M., MOTHES, B. \& LYRIO-OLIVEIRA, I. 2003. Redescription of Geodia papyracea (Hechtel, 1965) with new records along the northeastern and southeastern Brazilian coast. Boll. Mus. Ist. Biol. Univ. Genova 68:605-612.

SILVA, C.M.M., SILVA, M. \& COSME, B 2007. Redescription of the Brazilian endemic sponge Geodia glariosa (Demospongiae: Geodiidae), with new records on its geographic and bathymetric distribution. In Porifera research: biodiversity, innovation and sustainability (M.R. Custódio, G. Lôbo-Hajdu, E. Hajdu \& G. Muricy, ed.). Série Livros 28. Museu Nacional, Rio de Janeiro, p.593-602.

SIPKEMA, D., FRANSSEN, M.C.R., OSINGA, R., TRAMPER, J. \& WIJFFELS, R.H. 2005. Marine sponges as pharmacy. Mar. Biotechnol. 7:142-162. http://dx.doi.org/10.1007/s10126-004-0405-5

SUMIDA, P.Y.G., YOSHINAGA, M.Y., MADUREIRA, L.A.S.P. \& HOVLAND, M. 2004. Seabed pockmarks associated with deepwater corals off SE Brazilian continental slope, Santos Basin. Mar. Geol. 207:59-167. http://dx.doi.org/10.1016/j.margeo.2004.03.006

TURON, X., MERITXELL, C., TARJUELO, I., URIZ, M.J. \& BECERRO, M.A. 2000. Mass recruitment of Ophiothrix fragilis (Ophiuroidea) on sponges: settlement patterns and post-settlement dynamics. Mar. Ecol. Prog. Ser. 200:201-12. http://dx.doi.org/10.3354/meps200201

VACELET, J. \& DONADEY, C. 1977. Electron microscope study of the association between some sponges and bacteria. J. Exp. Mar. Biol. Ecol. 30:301-314. http://dx.doi.org/10.1016/0022-0981(77)90038-7

VAN SOEST, R.W.M. \& HAJDU, E. 2000. New species of Desmanthus (Porifera, Demospongiae) with a discussion of its ordinal relationships. Zoosystemas 22(2):299-312.

VAN SOEST, R.W.M., BOURY-ESNAULT, N., HOOPER, J.N.A., RÜTZLER, K., DE VOOGD, N.J., ALVAREZ, B., HAJDU, E., PISERA, A.B., VACELET, J., MANCONI, R., SCHOENBERG, C., JANUSSEN, D., TABACHNICK, K.R. \& KLAUTAU, M. 2008. World Porifera Database. Disponível em http://www.marinespecies.org/porifera (último acesso em 07/2010).

VILANOVA, E.P. 2003. Taxonomia de esponjas da família Dysideidae (Demospongiae: Dictyoceratida) na costa brasileira. Dissertação de Mestrado, Universidade Federal do Rio de Janeiro.

VOLKMER-RIBEIRO, C. 1979. Evolutionary study of genus Metania Gray, 1867 (Porifera - Spongillidae). I. The new species. Amazoniana 6(4):639-649.

VOLKMER-RIBEIRO, C. 1986. Evolutionary study of the freshwater sponge genus Metania Gray, 1867:III - Metaniidae, new family. Amazoniana 9(4):493-509.

VOLKMER-RIBEIRO, C. 1999. Porifera. In Biodiversidade do Estado de São Paulo: síntese do conhecimento ao final do século XX. Invertebrados de água doce (D. Ismael, W.C. Valenti, T. Matsumura-Tundisi \& O. Rocha, ed.). FAPESP, São Paulo, v.4. p.1-9.

VOLKMER-RIBEIRO, C., BICHUETTE, M.E. \& MACHADO, V.S. 2010. Racekiela cavernicola (Porifera: Demospongiae). New species and the first record of cave freshwater sponge from Brazil. Neotropical Biol. Conserv. 5:53-58. http://dx.doi.org/10.4013/nbc.2010.51.08

VOLKMER-RIBEIRO, C. \& COSTA, P.R.C. 1992. On Metania spinata (Carter, 1881) and Metania kiliani n.sp. - Porifera, Metaniidae VolkmerRibeiro, 1986. Amazoniana 12(1):7-16.

VOLKMER-RIBEIRO, C. \& TAVARES, M.C.M. 1993. Sponges from the flooded sandy beaches of two Amazon clear water rivers (Porifera). Iheringia 75:81-101.

VOLKMER-RIBEIRO, C., TAVARES, M.C.M. \& FURSTENAU-OLIVEIRA, K. 2009. Acathotylotra alvarengai (Porifera, Demospongiae). New genus and species of sponge from Tocantins river, State of Pará, Brazil. Iheringia 99:345-348. http://dx.doi.org/10.1590/S0073-47212009000400002 
WEISZ, J.B., LINDQUIST, N., MARTENS, C.S. 2008. Do associated microbial abundances impact marine demosponge pumping rates and tissue densities? Oecologia 155:367-376. http://dx.doi.org/10.1007/ s00442-007-0910-0

WILKINSON, C.R. 1978. Microbial associations in sponges. I. Ecology, physiology and microbial populations of coral reef sponges. Mar. Biol. 49:161-167. http://dx.doi.org/10.1007/BF00387115
ZILBERBERG, C., SOlÉ-CAVA, A.M. \& KLAUTAU, M. 2006. The extent of asexual reproduction in sponges of the genus Chondrilla (Demospongiae: Chondrosida) from the Caribbean and the Brazilian coasts. J. Exp. Mar. Biol. Ecol. 336(2):211-220. http://dx.doi. org/10.1016/j.jembe.2006.05.010

ZILBERBERG, C., KLAUTAU, M., MENEGOLA, C., BERLINCK, R. \& HAJDU, E. 2009. Porifera. In Estado da arte e perspectivas para a Zoologia no Brasil (R.M. Rocha \& W.A. Boeger). Editora UFPR, p.17-28.

Recebido em 27/07/2010 Versão reformulada recebida em 08/10/2010 Publicado em 15/12/2010 


\section{Apêndices}

Apêndice 1. Principais coleções de Porifera no Brasil.

Appendix 1. Main sponge collections in Brazil.

\begin{tabular}{|c|c|c|c|}
\hline Coleções & Lotes & Local & Curador \\
\hline MNRJ & $\begin{array}{c}14.500 \\
(\text { SP: } 1000)\end{array}$ & Departamento de Invertebrados, Museu Nacional, UFRJ (RJ) & Prof. Eduardo Hajdu \\
\hline MCN/FZB & 7.500 & Museu de Ciências Naturais. Fundação Zoobotânica (RS) & $\begin{array}{c}\text { Profa. Cecília Volkmer-Ribeiro } \\
\text { (esponjas de águas continentais), } \\
\text { e Profa. Clea Lerner } \\
\text { (esponjas marinhas) }\end{array}$ \\
\hline UFRJPOR & 5.600 & Departamento de Invertebrados, Museu Nacional, UFRJ (RJ) & Prof. Guilherme Muricy \\
\hline MZ/UFBA & 5.000 & Museu de Zoologia, UFBA (BA) & Profá. Carla MM Silva \\
\hline DO/UFPE & 1.260 & Departamento de Oceanografia, UFPE (PE) & Não há \\
\hline MZUSP & 128 & Museu de Zoologia, USP (SP) & Não há \\
\hline
\end{tabular}

Apêndice 2. Pesquisadores no Brasil.

Appendix 2. Researchers in Brazil.

\begin{tabular}{|c|c|c|}
\hline Nomes & Áreas principais de atuação & Vínculo \\
\hline Batista, Twiggy C.A. & Sistemática & Secretaria de Estado da Saúde (Palmas, TO) \\
\hline Berlinck, Roberto G.S. & Química de produtos naturais & Depto. de Físico Química. USP (São Carlos, SP) \\
\hline Borojevic, Radovan & $\begin{array}{c}\text { Biologia celular, } \\
\text { evolução e taxonomia }\end{array}$ & $\begin{array}{c}\text { Depto. de Histologia e Embriologia. } \\
\text { UFRJ (Rio de Janeiro, RJ) }\end{array}$ \\
\hline Coutinho, Cristiano & $\begin{array}{l}\text { Biologia celular, evolução e } \\
\text { biologia do desenvolvimento }\end{array}$ & $\begin{array}{c}\text { Depto. de Histologia e Embriologia. } \\
\text { UFRJ (Rio de Janeiro, RJ) }\end{array}$ \\
\hline Custódio, Márcio R. & Biologia celular e fisiologia & Depto. de Fisiologia Geral. USP (São Paulo, SP) \\
\hline Hajdu, Eduardo & $\begin{array}{c}\text { Sistemática, biogeografia } \\
\text { e evolução } \\
\end{array}$ & $\begin{array}{c}\text { Depto. de Invertebrados. Museu Nacional. } \\
\text { UFRJ (Rio de Janeiro, RJ) }\end{array}$ \\
\hline Klautau, Michelle & Sistemática, evolução, reprodução e ecologia & Depto. de Zoologia. UFRJ (Rio de Janeiro, RJ) \\
\hline Lerner, Cléa B. & Sistemática & $\begin{array}{l}\text { Museu de Ciências Naturais. Fundação Zoobotânica } \\
\text { (Porto Alegre, RS) }\end{array}$ \\
\hline Lôbo-Hajdu, Gisele & $\begin{array}{c}\text { Sistemática, genética de } \\
\text { populações e biogeografia }\end{array}$ & $\begin{array}{c}\text { Depto. de Biologia Celular e Genética. } \\
\text { UERJ (Rio de Janeiro, RJ) }\end{array}$ \\
\hline Mothes, Beatriz & Sistemática & $\begin{array}{c}\text { Museu de Ciências Naturais. Fundação Zoobotânica } \\
\text { (Porto Alegre, RS) }\end{array}$ \\
\hline Muricy, Guilherme & $\begin{array}{l}\text { Sistemática, ecologia } \\
\text { e farmacologia }\end{array}$ & $\begin{array}{c}\text { Depto. de Invertebrados. Museu Nacional. } \\
\text { UFRJ (Rio de Janeiro, RJ) }\end{array}$ \\
\hline Pinheiro, Ulisses S & Sistemática & Depto. de Zoologia. UFPE (Recife, PE) \\
\hline Silva, Carla M.M. & Sistemática & Depto. de Zoologia. UFBA (Salvador, BA) \\
\hline Solé-Cava, Antônio M. & Genética de populações e sistemática & Depto. de Genética. UFRJ (Rio de Janeiro, RJ) \\
\hline $\begin{array}{l}\text { Volkmer-Ribeiro, } \\
\text { Cecília }\end{array}$ & $\begin{array}{c}\text { Sistemática, evolução ecologia } \\
\text { e paleontologia }\end{array}$ & $\begin{array}{c}\text { Museu de Ciências Naturais. } \\
\text { Fundação Zoobotânica (Porto Alegre, RS) }\end{array}$ \\
\hline
\end{tabular}

Apêndice 3. Sites de interesse

Appendix 3. Web resources.

\begin{tabular}{|c|c|}
\hline Porifera Brasil & www.poriferabrasil.mn.ufrj.br/ \\
\hline Sponge Barcoding Project & www.spongebarcoding.org \\
\hline World Porifera Database & www.marinespecies.org/porifera/ \\
\hline
\end{tabular}

